ARTICLE

\title{
Linking DNA repair and cell cycle progression through serine ADP-ribosylation of histones
}

Julien Brustel ${ }^{1}$, Tetsuya Muramoto (1D ${ }^{2}$, Kazuki Fumimoto ${ }^{2}$, Jessica Ellins ${ }^{1}$, Catherine J. Pears (1D ${ }^{1} \&$ Nicholas D. Lakin (1D) ${ }^{1 \times}$

Although serine ADP-ribosylation (Ser-ADPr) by Poly(ADP-ribose)-polymerases is a cornerstone of the DNA damage response, how this regulates DNA repair and genome stability is unknown. Here, we exploit the ability to manipulate histone genes in Dictyostelium to identify that ADPr of the histone variant $\mathrm{H} 3 \mathrm{~b}$ at $\mathrm{S} 10$ and $\mathrm{S} 28$ maintains genome stability by integrating double strand break (DSB) repair with mitotic entry. Given the critical requirement for mitotic H3510/28 phosphorylation, we develop separation of function mutations that maintain $S 10$ phosphorylation whilst disrupting ADPr. Mechanistically, this reveals a requirement for $\mathrm{H} 3 \mathrm{bS} 10 / 28 \mathrm{ADPr}$ in non-homologous end-joining by recruiting Ku to DSBs. Moreover, this also identifies $\mathrm{H} 3 \mathrm{bS} 10 / \mathrm{S} 28 \mathrm{ADPr}$ is critical to prevent premature mitotic entry with unresolved DNA damage, thus maintaining genome stability. Together, these data demonstrate how serine ADPr of histones coordinates DNA repair with cell cycle progression to maintain genome stability.

\footnotetext{
${ }^{1}$ Department of Biochemistry, University of Oxford, South Parks Road, Oxford, UK. ${ }^{2}$ Department of Biology, Faculty of Science, Toho University, Funabashi,

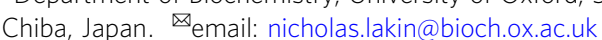


oly(ADP-ribose) polymerases (PARPs) catalyse the $\mathrm{NAD}^{+}$. dependent addition of single ADP-ribose moieties or chains onto target proteins by mono- or poly-ADP-ribosylation, respectively. ADP-ribosylation (ADPr) has been implicated in a wide variety of cellular processes including cell growth and differentiation, transcriptional regulation and programmed cell death ${ }^{1}$. However, the best established role of this modification is in maintaining genome integrity through DNA repair ${ }^{2}$.

Of the 17 genes that contain PARP catalytic domains several have been implicated in the DNA damage response, including PARP1 and PARP2 that catalyse poly-ADPr, and PARP3 that performs mono-ADPr ${ }^{3}$. PARPs are critical for the repair of DNA strand breaks by ADP-ribosylating factors at DNA lesions to promote the recruitment of chromatin remodelling and repair factors through PAR-interaction domains present in these proteins. For example, PARP1 and PARP2 are activated upon binding to SSBs and through ADPr of target proteins at the break, promote XRCC1 and ALC1 recruitment to damage sites to regulate the assembly and turnover of additional factors that facilitate DNA repair ${ }^{4-10}$. In contrast, PARP3 responds to DNA DSBs, promoting the assembly of non-homologous end-joining (NHEJ) factors at DNA lesions ${ }^{11,12}$. Whilst PARP1 has also been implicated in remodelling chromatin at DSBs to promote $\mathrm{NHEJ}^{13}$, it is also required for alternative-NHEJ, a pathway that employs micro-homology-based repair to resolve DSBs in the absence of conventional NHEJ ${ }^{14}$. PARP1 and PARP2 also regulate replication-associated mechanisms including Okazaki fragment processing ${ }^{15}$ and replication-associated repair by promoting Mre11 recruitment to stalled/damaged replication forks ${ }^{16-18}$, maintaining regressed forks by inhibiting the RECQ1 helicase ${ }^{19}$, and stabilising homologous recombination (HR) factors at these structures $^{5}$.

However, whilst the pathways that PARPs function in to maintain genome integrity are becoming increasingly welldefined, the mechanistic basis of this regulation is less clear. ADPr of nuclear proteins, most notably histones, has been known for many years ${ }^{20}$. However, it is not until recently that advances in mass spectrometry have provided a detailed map of the ADPribosylome ${ }^{21-25}$. Glutamate (Glu; D) and aspartate (Asp; E) were initially identified as key ADP-ribose acceptors and site-specific ADPr of these amino acids has been implicated in DNA repair and cell type specification ${ }^{26-29}$. However, ADPr of Glu and Asp are relatively low abundance events following genotoxic stress. Instead, a key advance in our understanding was the identification of histone PARylation factor 1 (HPF1), a PARP1/PARP2 interacting protein that directs ADPr of histones and other target proteins on serine $e^{24,30}$. Serine is the major acceptor for ADPribose in response to DNA damage, and all core histones are $\mathrm{ADPr}$ in response to genotoxic stress, predominantly in the context of a KS motif ${ }^{23,31}$. Given the high density of posttranslational modifications (PTMs) within histone tails, serine ADPr (Ser-ADPr) can impact on modification of other sites within histones such as lysine acetylation ${ }^{32,33}$. Indeed, Ser-ADPr itself may block the ability to phosphorylate these amino acids and vice versa ${ }^{34}$, suggesting these PTMs may have opposing roles in regulating variety processes. However, the functional significance of these relationships is unknown.

This lack of mechanistic insight is due, in part, to the absence of an appropriate experimental platform to assess the role of sitespecific histone ADPr events in vivo. Multiple copies of core histone genes in vertebrates make the manipulation of specific PTM sites at endogenous histone loci challenging. This is exacerbated by the absence of PARPs in commonly used model organisms to study DNA repair where this technology is available, precluding an analysis of histone ADPr in these systems. In this context, the amoeba Dictyostelium discoidium is an ideal model organism to study histone ADPr in DNA repair and genome stability. We and others identified a number of vertebrate DNA repair components in Dictyostelium that are lost or show limited conservation in other model organisms used to study the DNA damage response (DDR) ${ }^{35-39}$. This is particularly striking with PARPs and the mechanistic basis of how these enzymes regulate DNA DSB repair is conserved with vertebrates $35,40-43$. Dictyostelium is also ideally suited to study how site-specific modification of histones regulates a variety of processes. It contains a wider variety of histone variants that are more similar to vertebrates than other simple eukaryotic model organisms ${ }^{44-46}$. The major PTMs on histones are also observed in this organism, including $\mathrm{ADPr}^{45-49}$. Importantly, Dictyostelium also contains single copy histone genes that are amenable to genetic manipulation, opening up the possibility to perform gene replacement and site-specific mutation strategies to assess the functional significance of histone PTMs ${ }^{45,50,51}$.

Recently, we exploited these unique characteristics of Dictyostelium to develop this organism as a model to identify site-specific ADPr events and characterise how they regulate DNA repair and genome stability 43,50 . Here we build on these studies, using this system to identify that serine ADPr (Ser-ADPr) is conserved in Dictyostelium and to assess how Ser-ADPr of histones coordinates DNA repair and mitotic entry following genotoxic stress to maintain genome stability.

\section{Results}

The histone variant $\mathrm{H} 3 \mathrm{~b}$ is required to maintain genome stability through DNA DSB repair. Given the ability to manipulate histone genes in Dictyostelium and that histone $\mathrm{H} 3$ is a major acceptor of ADP-ribose in response to DNA damage in vertebrates $23,31,52$, we assessed the impact of manipulating the two major Dictyostelium H3 variant genes on genome stability and DNA repair. Despite repeated attempts no strains with disruption of the $h 3 a$ gene have been generated, suggesting an essential requirement for this histone variant in Dictyostelium cells. In contrast, an $h 3 b$ null strain has been successfully generated $\left(h 3 b^{-}\right)^{45}$ and strikingly, these cells exhibit elevated levels of abnormal nuclear morphology relative to parental Ax2 cells (Fig. 1a). More than $80 \%$ of these nuclei exhibit $\gamma \mathrm{H} 2 \mathrm{AX}$ staining (Supplementary Fig. 1A), suggesting they represent cells with increased genome instability and/or DNA damage. Abnormal nuclear morphology is elevated in untreated $h 3 b^{-}$relative to Ax2, rather than dramatically increasing in response to phleomycin, suggesting genome instability may be a consequence of spontaneous or endogenous DNA damage (Fig. 1a, left panel). Nevertheless, the $h 3 b^{-}$strain is more sensitive to phleomycin relative to Ax2 cells (Fig. 1b), suggesting an inability of these cells to repair DNA strand breaks. Additionally, whilst induction and decay rates of $\gamma \mathrm{H} 2 \mathrm{AX}$ are similar in Ax 2 and $h 3 b^{-}$cells following a transient exposure to phleomycin (e.g. Fig. 1c, d and Supplementary Fig. 1B), recovery is delayed in the $h 3 b^{-}$strain, further supporting a requirement for $\mathrm{H} 3 \mathrm{~b}$ in initiating repair of DNA damage.

Given the striking conservation of vertebrate DSB components in Dictyostelium ${ }^{36-39}$, we considered whether these pathways are compromised in the $h 3 b^{-}$strain. Strains defective in the key HR gene exonuclease $I\left(\right.$ exol $\left.^{-}\right)$are sensitive to DNA DSBs. However, $h 3 b^{-}$cells show radiosensitivity between Ax2 and exo1 ${ }^{-}$cells, similar to that observed for a NHEJ-defective strain $\left(k u 80^{-}\right.$; Supplementary Fig. 2A), suggesting disruption of $h 3 b$ results in defective NHEJ rather than HR. Recruitment of repair factors to DSBs through PAR-binding motifs is a key step in initiating NHEJ in vertebrates ${ }^{11}$ and Dictyostelium ${ }^{35}$. Therefore, we also considered whether $\mathrm{H} 3 \mathrm{~b}$ is required for assembly of NHEJ and/or 
a

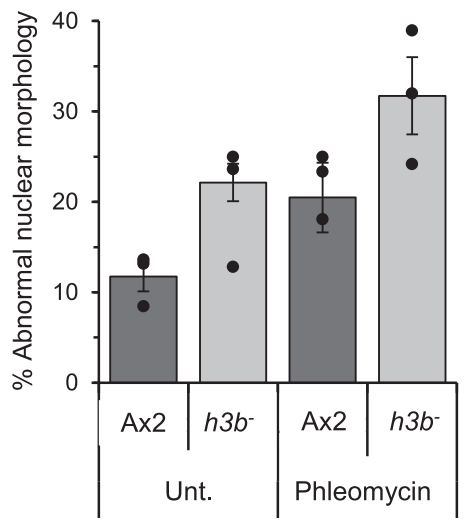

b

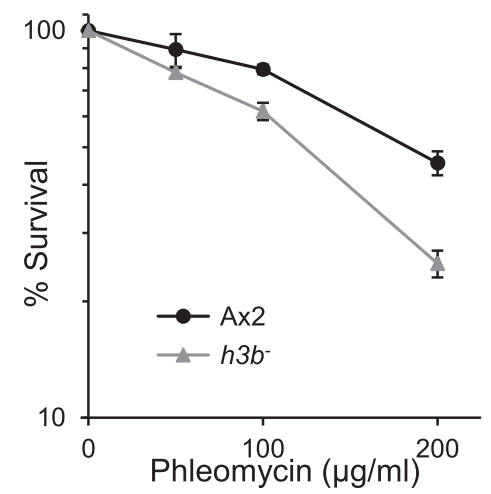

d

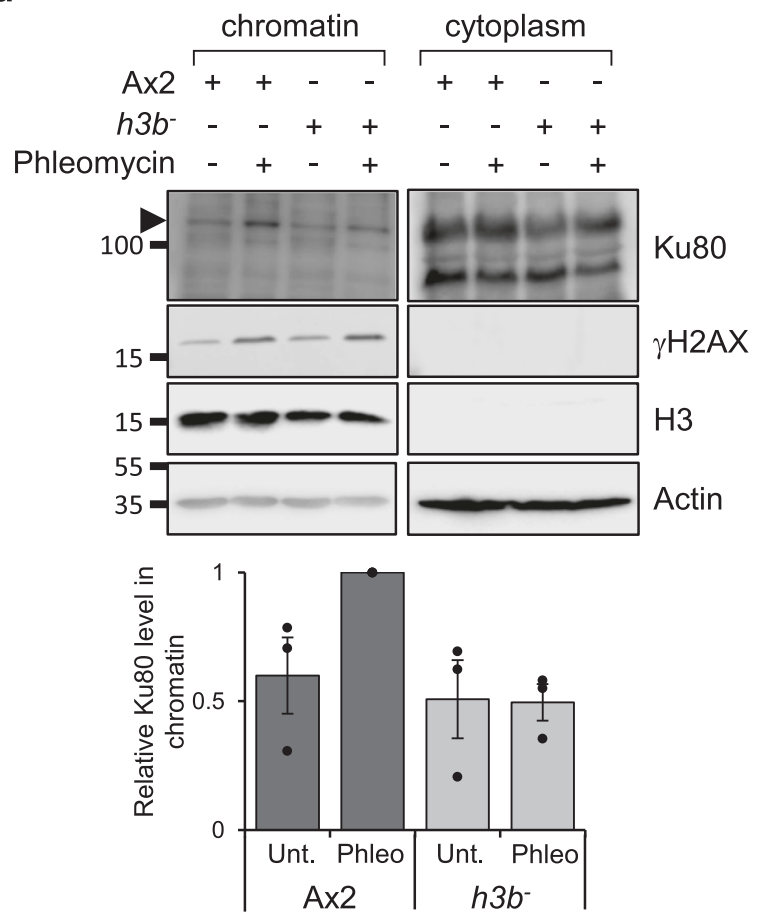

Abnormal nuclear morphology

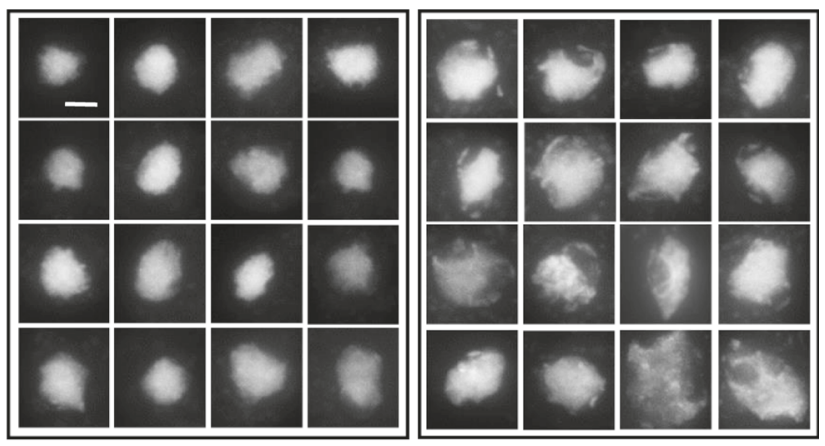

C

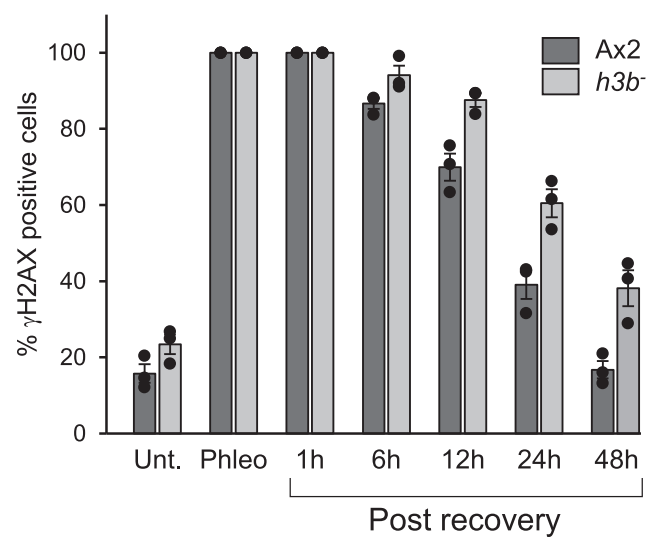

e

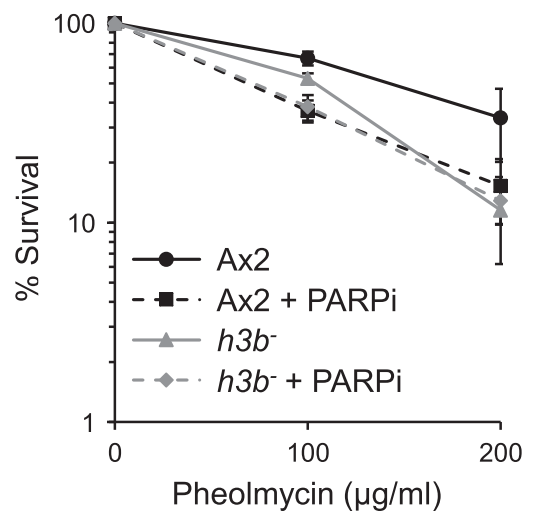

HR factors in chromatin following DSBs. Whilst we see robust enrichment of Ku80 in chromatin in response to DSBs in Ax2 cells, this is reduced in the $h 3 b^{-}$strain (Fig. 1d). In contrast, assembly of Rad51 in chromatin following DSBs is similar in Ax2 and $h 3 b^{-}$cells, supporting the hypothesis that $\mathrm{HR}$ is not dependent on H3b (Supplementary Fig. 2B). Taken together, these data indicate that whilst loss of $\mathrm{H} 3 \mathrm{~b}$ has little impact on markers of HR, it results in defective DNA repair that is reflected in a reduced ability to assemble NHEJ factors such as Ku80 at sites of DNA damage.

Histone H3b is ADPr on serines in response to DNA DSBs. Our previous work identified that disruption of the Dictyostelium PARP Adprtla results in radiosensitivity and an inability to recruit the Ku heterodimer to DNA DSBs via a PAR-interaction 
Fig. 1 H3b is required for DSB repair and genome stability. a Abnormal nuclear morphology in the $h 3 b^{-}$strain. Left panel: Quantification of cells displaying abnormal nuclear morphology in Ax2 or $h 3 b^{-}$cells either in control conditions or $48 \mathrm{~h}$ after a $1 \mathrm{~h}$ exposure to phleomycin ( $n=3$; individual data points are shown, error bars represent the SEM). Right panel: representative pictures of healthy and abnormal nuclei. DNA is stained with DAPI and each nucleus has a diameter of $14.5 \mu \mathrm{m}$. Scale bar represents $5 \mu \mathrm{m}$. b Ax2 or $h 3 b^{-}$cells were exposed to phleomycin for $1 \mathrm{~h}$ at the indicated concentrations and cell survival assessed by clonogenic survival assays (data represent three biological repeats, error bars represent the SEM). c Ax2 or $h 3 b^{-}$cells were treated for $1 \mathrm{~h}$ with phleomycin and following recovery in fresh media, cells with $>5 \gamma \mathrm{H} 2 \mathrm{AX}$ foci assessed by immunofluorescence. (data represent three biological repeats; individual data points are shown, error bars represent the SEM). d Following exposure of Ax2 or h3b- cells to phleomycin for $1 \mathrm{~h}$, cytoplasmic and chromatin fractions were prepared from cells and western blotting performed using the indicated antibodies (left panel). Enrichment of Ku80 in chromatin fractions was quantified from three independent experiments (right panel). Molecular weight markers are indicated in kDa. e Ax2 or $h 3 b^{-}$cells were exposed to phleomycin for $1 \mathrm{~h}$ at the indicated concentrations either the absence or presence of olaparib (PARPi) and cell survival assessed by clonogenic survival assays (data represent four biological repeats; error bars represent the SEM). Source data are provided in the Source Data file.

domain in $\mathrm{Ku} 70^{35,40}$. Given the similarity of these phenotypes with $h 3 b^{-}$cells (Fig. 1 ), we considered the possibility that these events are regulated through $\mathrm{ADPr}$ of $\mathrm{H} 3 \mathrm{~b}$. Consistent with this hypothesis, whilst PARP inhibitors (PARPi) sensitise parental Ax2 cells to DSBs induced by phleomycin, they do not further sensitise $h 3 b^{-}$cells to DNA damage, indicating that PARPs and $\mathrm{H} 3 \mathrm{~b}$ likely function in the same pathway with regards radioresistance (Fig. 1e and Supplementary Fig. 2C).

To further assess the link between ADPr of $\mathrm{H} 3 \mathrm{~b}$ and DNA repair, we next assessed whether this histone variant is ADPr in response to DSBs. Vertebrate histones, including $\mathrm{H} 3$, are ADPr on serine in response to genotoxic stress ${ }^{23}$. Therefore, we investigated whether Ser-ADPr similarly occurs in Dictyostelium. We detect Adprt1a/Adprt2-dependent ADPr in Dictyostelium whole-cell extracts using an antibody that recognises HPF1dependent ADPr events in vivo and therefore represents largely Ser-ADPr (D33205; Fig. 2a) ${ }^{34}$. A variety of bands that are recognised by D33205 are induced upon DNA damage, suggesting serine may be ADP-ribosylated on a variety of substrates in response to DSBs. Several lower molecular weight proteins are recognised by D33205 and consistent with these protein species representing histones, they co-purify with basic proteins during acid extraction, a protocol that enriches for histone proteins ${ }^{45}$ (Fig. 2b). To more directly investigate whether $\mathrm{H} 3 \mathrm{~b}$ is a target for Ser-ADPr, we expressed Flag-tagged H3b (Flag-H3b ${ }^{\mathrm{wt}}$ ) in the $h 3 b^{-}$strain. Flag-H3b immunoprecipitated from cells is recognised by D33205 and this signal is induced upon induction of DNA damage by phleomycin (Fig. 2c). Taken together, these data indicate that Ser-ADPr is conserved in Dictyostelium and that histone $\mathrm{H} 3 \mathrm{~b}$ is a target for this PTM in response to DNA damage.

Next, we assessed which sites on $\mathrm{H} 3 \mathrm{~b}$ are ADPr in response to DSBs. Studies in vertebrates reveal that serines 10 (S10) and 28 (S28) are the main ADPr acceptors on histone $\mathrm{H} 3$ in response to DNA damage $23,31,52$. S10 and S28 are conserved in Dictyostelium $\mathrm{H} 3 \mathrm{~b}$, whilst $\mathrm{H} 3 \mathrm{a}$ is conserved only at S10 (Fig. 2d). To assess whether H3b S10 and S28 are ADP-ribosylated, we expressed Flag-tagged $\mathrm{H} 3 \mathrm{~b}$ bearing mutations at $\mathrm{S} 10$ (Flag-H3b ${ }^{\mathrm{S} 10 \mathrm{~A}}$ ) or S28 (Flag-H3b ${ }^{\mathrm{S} 28 \mathrm{~A}}$ ) in $h 3 b^{-}$cells and assessed ADPr following DNA damage by western blotting of histone-enriched acid extracts with a reagent that recognises poly- and mono-ADPr proteins. Consistent with ADPr of recombinant $\mathrm{H} 3 \mathrm{~b}$, a higher molecular weight DNA damage-induced species is apparent specifically in Flag-H3b ${ }^{\mathrm{WT}}$ expressing cells relative to non-expressing Ax 2 cells (Fig. 2e). This ADPr species is also apparent in cells expressing either Flag-H3b $b^{\mathrm{S} 10 \mathrm{~A}}$ or Flag-H3b $\mathrm{b}^{\mathrm{S} 28 \mathrm{~A}}$, indicating that mutation of these amino acids alone does not significantly impact on the ability of $\mathrm{H} 3 \mathrm{~b}$ to be ADP-ribosylated in response to DNA DSBs. Together, these data indicate that whilst $\mathrm{H} 3 \mathrm{~b}$ is robustly ADPribosylated in response to DNA DSBs, either S10/S28 are not modified, or that similar to vertebrates ${ }^{31}$ these events are not exclusive to either of these amino acids.
Mutations that maintain phosphorylation whilst disrupting Ser-ADPr reveal $\mathrm{H} 3 \mathrm{~b} \mathrm{S10}$ and $\mathrm{S} 28$ are ADPr in response to DNA DSBs. Given that disruption of S10 or S28 does not disrupt $\mathrm{H} 3 \mathrm{~b} \mathrm{ADPr}$, we attempted to mutate these sites in combination. However, despite repeated attempts, we were unable to express Flag-H3b $\mathrm{b}^{\mathrm{S} 10 \mathrm{AS} 28 \mathrm{~A}}$ in the $h 3 b^{-}$strain, suggesting that expression of this mutant is toxic to cells. Phosphorylation of S10 and S28 by Aurora A and Aurora B is a common marker of mitotic entry and these modifications are critical for faithful mitotic progression in a variety of organisms ${ }^{53}$. Given phosphorylation of Dictyostelium $\mathrm{H} 3$ at $\mathrm{S} 10$ is detected by mass spectrometry ${ }^{46}$, we considered the possibility that toxicity of the Flag- $\mathrm{H} 3 \mathrm{~b}^{\mathrm{S10AS} 28 \mathrm{~A}}$ mutant is a consequence of deregulated cell cycle progression due to defective H3 phosphorylation during mitosis. We therefore developed a mutation strategy to separate the function of H3b ADPr and phosphorylation, allowing us to establish the biological significance of $\mathrm{H} 3$ ADPr without impacting on its phosphorylation status during the cell cycle.

To address this question, we initially developed an assay to assess $\mathrm{H} 3$ phosphorylation and ADPr during mitosis. Cells were synchronised in the G2 phase of the cell cycle using standard procedures $^{40}$ and following release from this block, progression through mitosis assessed by monitoring synchronous cell doubling (Fig. 3a). Consistent with H3 S10 phosphorylation during mitosis, arresting these cells at anaphase by release into nocodozole results in decoration of mitotic chromosomes with a H3S10-P phospho-specific antibody and induction of $\mathrm{H} 3$ phosphorylation during mitosis (Fig. 3b, c). To specifically assess the phosphorylation status of $\mathrm{H} 3 \mathrm{~b}$ during mitosis, Flag-H3b $\mathrm{b}^{\mathrm{WT}}$ was immunoprecipitated from asynchronous or mitotic arrested cells. Consistent with phosphorylation of $\mathrm{H} 3 \mathrm{~b}$ at $\mathrm{S} 10$ during mitosis, Flag-H3b $\mathrm{b}^{\mathrm{WT}}$ is recognised by the H3S10-P antibody and this is induced in mitotic arrested cells (Fig. 3d).

Whilst serine is the main target for DNA damage-induced ADPr, threonine is not ADP-ribosylated by PARP1/HPF1 in vitro $^{32}$ and has not been detected by MS in cells ${ }^{23,24}$. We therefore hypothesised that a S10T mutation will maintain phosphorylation at this site, whilst disrupting ADPr. Consistent with this idea, in contrast to expression of Flag-H3b $10 \mathrm{AS} 28 \mathrm{~A}$, $h 3 b^{-}$cells expressing Flag-H3b $\mathrm{b}^{\mathrm{S} 10 \mathrm{TS} 28 \mathrm{~A}}$ are viable and exhibit similar growth rates to $h 3 b^{-}$cells expressing wild-type Flag-H3b (Supplementary Fig. 3A), indicating this mutation combination is not toxic to cells. Moreover, Flag-H3b $\mathrm{b}^{\mathrm{S} 10 \mathrm{TS}} 28 \mathrm{~A}$ immunoprecipitated from mitotic extracts is recognised by the H3S10-P antibody, indicating this mutant is phospho-competent during mitosis (Fig. 3e). Next, we assessed the ADPr status of $\mathrm{H} 3 \mathrm{~b}^{\mathrm{S} 10 \mathrm{~T}}$, $\mathrm{H} 3 \mathrm{~b}^{\mathrm{S} 28 \mathrm{~A}}$ and Flag-H3b $\mathrm{b}^{\mathrm{S} 10 \mathrm{TS} 28 \mathrm{~A}}$ in response to DSBs. Whilst the $\mathrm{S} 10 \mathrm{~T}$ or S28A mutations reduce ADPr of $\mathrm{H} 3 \mathrm{~b}$, it is still evident, indicating both these residues are targeted independently of each other in response to DNA damage (Supplementary Fig. 4A). However, whilst DNA damage-induced ADPr of Flag-H3bWT is readily detectable in histone-enriched extracts or 
a

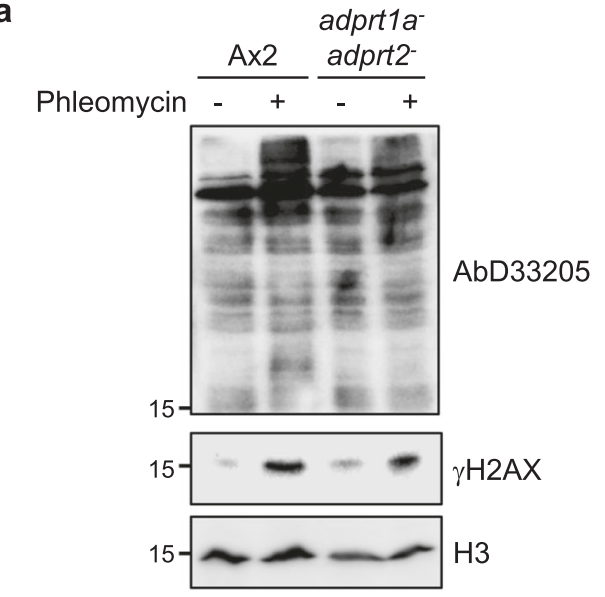

C

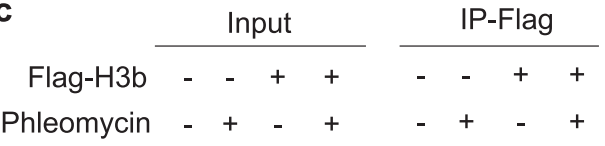

e

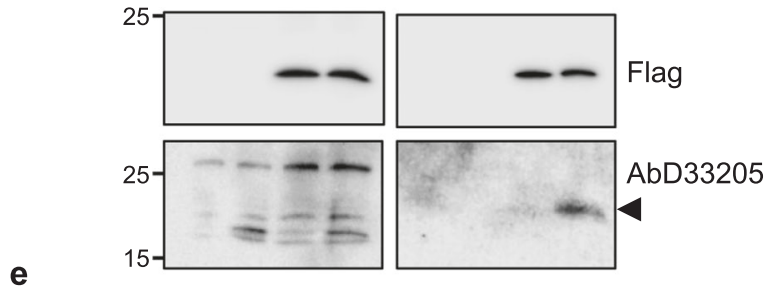

b

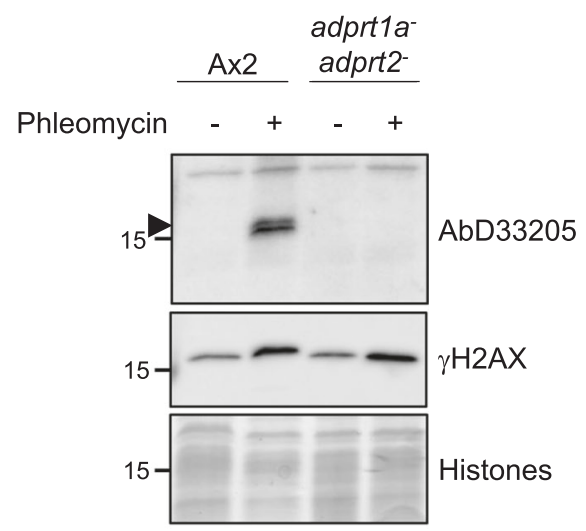

d

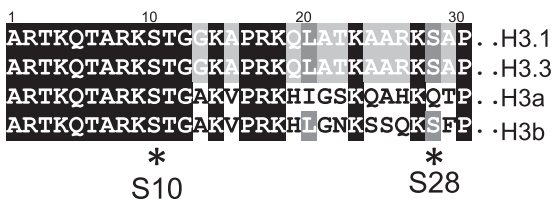

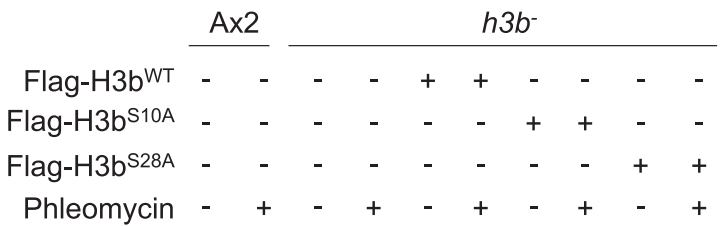
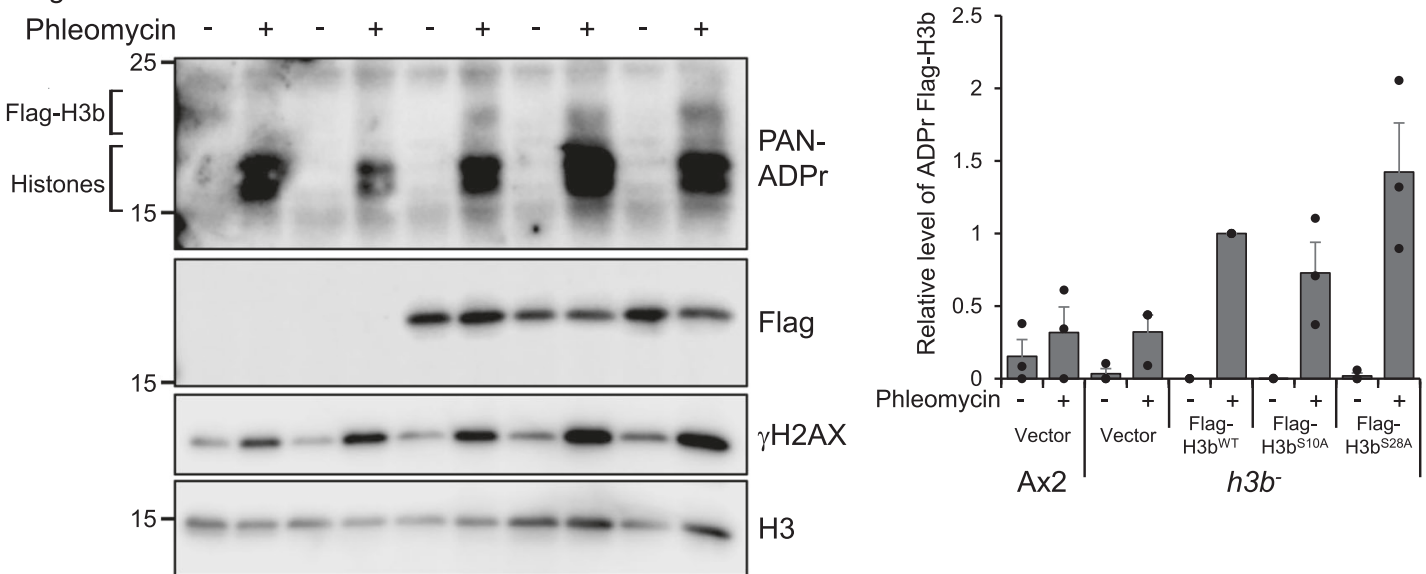

Fig. 2 H3b is ADP ribosylated on serine in response to DNA damage. a, $\mathbf{b}$ Ax2 or adprt1a ${ }^{-}$adprt2- cells were treated with phleomycin and whole cell (a) or acid (b) extracts western blotted with antibodies as indicated. Molecular weight markers are indicated in kDa. Representative pictures of three biological repeats are presented. $\mathbf{c} h 3 b^{-}$cells containing empty vector, or expressing Flag-H3bwt, were left untreated or exposed to phleomycin. Following preparation of denatured chromatin, Flag immunoprecipitation was performed. Input extracts or immunoprecipitates were subjected to Western blotting using the indicated antibodies. Molecular weight markers are indicated in $\mathrm{kDa}$. Representative pictures of at least three independent experiments. $\mathbf{d}$ Sequence comparison of human histone H3.1 and H3.3 with the Dictyostelium H3 variants $\mathrm{H} 3 \mathrm{a}$ and $\mathrm{H} 3 \mathrm{~b}$. S10 and S28, the main ADP-ribosylation targets in vertebrates are indicated. e Ax2 or $h 3 b^{-}$cells containing empty vector, or expressing Flag- $\mathrm{H} 3 b^{\mathrm{WT}}$, Flag- $\mathrm{H} 3 \mathrm{~b}^{\mathrm{S} 10 \mathrm{~A}}$ or Flag-H3b $\mathrm{S}^{\mathrm{A}} \mathrm{A}$ were left untreated or exposed to phleomycin. Following preparation of acid extracts, western blotting was performed using the indicated antibodies. ADP-ribosylated endogenous histones and Flag-H3b are highlighted. Enrichment of Flag-H3b in chromatin fractions was quantified (right panel; $n=3$; individual data points are shown and error bars represent the SEM). Molecular weight markers are indicated in kDa. Source data are provided in the Source Data file. 
a

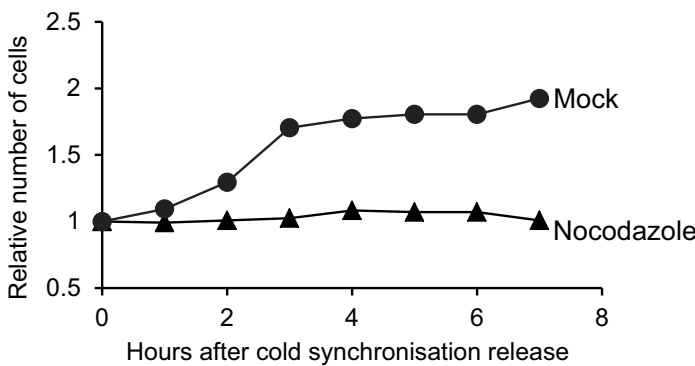

b

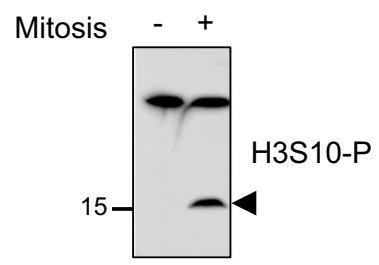

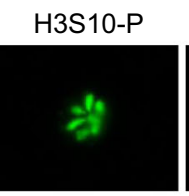

DAPI

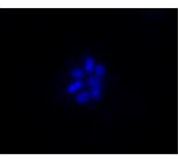

Merge

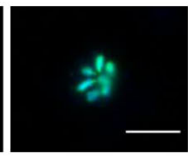

d

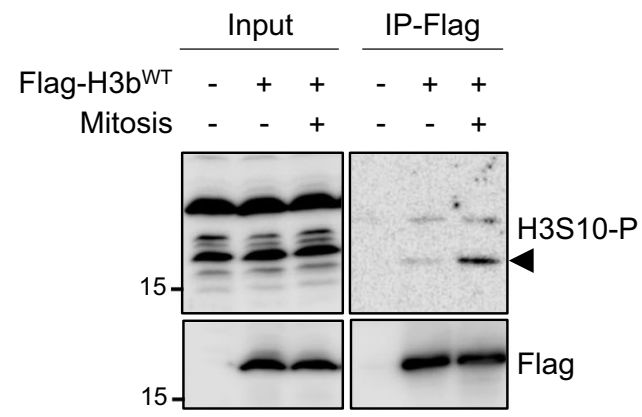

e

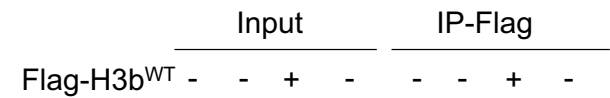

Flag-H3bS10T S28A - - $-+\quad-\quad+$

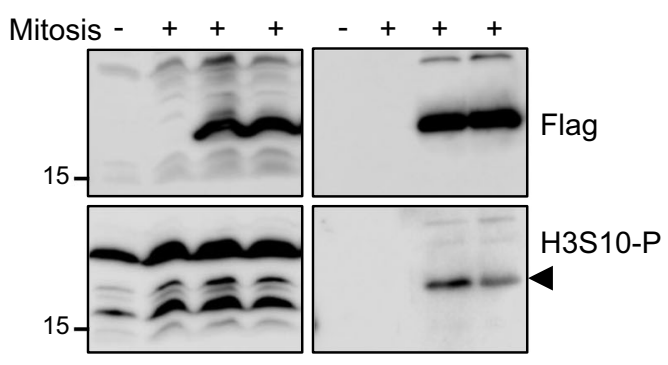

f
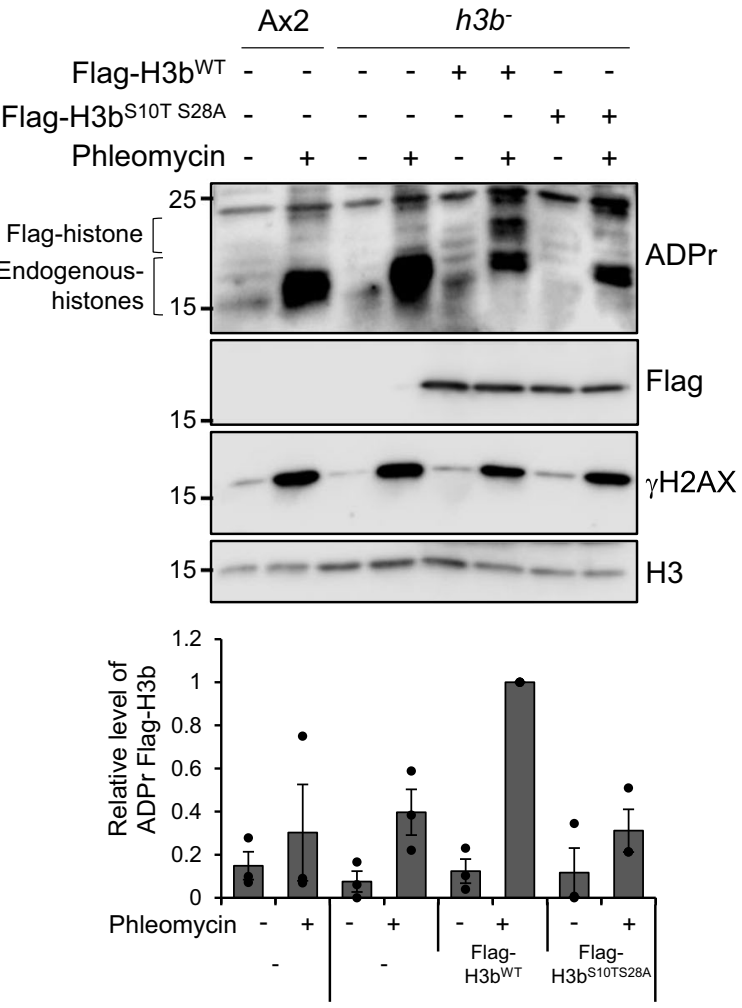

Ax2

g

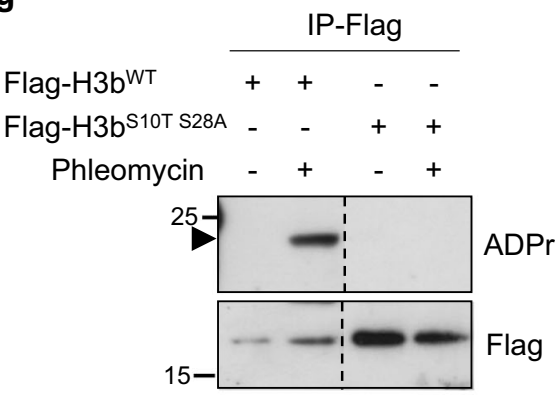

Fig. 3 Separation of function of H3b serine phosphorylation and ADP-ribosylation. a Ax2 cells were blocked in G2 and then released from cell cycle arrest in the absence or presence of nocodazole as indicated. Progression through mitosis was monitored by assessing cell numbers at times following release from G2. Quantification of one representative experiment from 3 biological repeats. b, c Asynchronous or nocodazole arrested Ax2 cells were subjected to Western blotting of whole cell extracts (b) or immunofluorescence (c) using an H3S10-P specific antibody. Molecular weight markers are indicated in $\mathrm{kDa}$. Scale bar $5 \mu \mathrm{m}$. d, e Cells containing empty vector or expressing Flag-H3bWT (d) and Flag-H3bWT or Flag-H3bS10TS28A (e) were left untreated or synchronised in mitosis with a nocodazole block as indicated. Input or Flag-immunoprecipitates were subjected to Western blotting using the indicated antibodies. Molecular weight markers are indicated in $\mathrm{kDa}$. $\mathbf{f}$ The indicated cell lines were left untreated or exposed to phleomycin. Western blotting of acid extracts was performed using the indicated antibodies. ADP-ribosylated endogenous histones and Flag-H3b are highlighted. Enrichment of Flag-H3b in chromatin fractions was quantified (lower panel; $n=3$; individual data points are shown and error bars represent the SEM). Molecular weight markers are indicated in $\mathrm{kDa} . \mathbf{g} h 3 b^{-}$cells expressing Flag-H3bWT or Flag-H3b $110 \mathrm{TS} 28 \mathrm{~A}$ were left untreated or exposed to phleomycin as indicated. Western blotting of Flag-immunoprecipitates was performed using the indicated antibodies. Molecular weight markers are indicated in kDa. All experiments represent at least three biological repeats. Source data are provided in the Source Data file. 
immunoprecipitates, we were unable to detect ADPr of Flag-

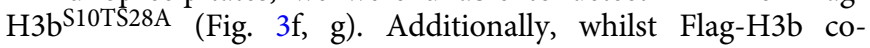
purified with ADP-ribosylated proteins affinity purified from phleomycin treated cells, Flag-H3b $\mathrm{b}^{\mathrm{S} 10 \mathrm{TS} 28 \mathrm{~A}}$ did not (Supplementary Fig. 3B). Taken together these data indicate S10 and S28 of $\mathrm{H} 3 \mathrm{~b}$ are ADP-ribosylated in response to DNA DSBs. Critically, they also indicate that in the context of $\mathrm{H} 3 \mathrm{bS} 10$, generating $\mathrm{S}$ to $\mathrm{T}$ mutants disrupts ADPr whilst maintaining phosphorylation, offering the opportunity to separate the function of phosphorylation and ADPr in a variety of processes.

ADPr of $\mathrm{H3bS10/S28}$ is necessary for efficient DSBs repair via NHEJ. Having established that S10 and S28 of H3b are ADPribosylated in response to DSBs, we next wished to assess whether these modifications contribute to the ability of cells to repair DNA damage. Initially, we investigated the requirement for $\mathrm{H} 3 \mathrm{~b}$ ADPr in tolerance to DNA DSBs. Consistent with S10T or S28A mutations only partially reducing $\mathrm{H} 3 \mathrm{~b} \mathrm{ADPr}$, whilst expression of Flag-H3b $\mathrm{b}^{\mathrm{wt}}$ is able to complement the radiosensitivity of the $h 3 b^{-}$ strain, expression of Flag-H3b ${ }^{\mathrm{S} 10 \mathrm{~T}}$ and Flag-H3b $\mathrm{b}^{\mathrm{S} 28 \mathrm{~A}}$ only partially rescue this phenotype (Supplementary Fig. 4B). However, $h 3 b^{-}$cells expressing Flag-H3b $\mathrm{b}^{\mathrm{S10TS} 28 \mathrm{~A}}$ remain as sensitive to phleomycin as control cells, indicating that defective $\mathrm{H} 3 \mathrm{~b}$ ADPr at S10 and S28 is associated with a significant increase in sensitivity to DNA DSBs (Fig. 4a and Supplementary Fig. 4B). Additionally, whilst PARPi sensitise parental $h 3 b^{-}$cells expressing Flag-H3b $\mathrm{b}^{\mathrm{WT}}$ to phleomycin, they do not induce further radiosensitivity in Flag-H3b ${ }^{\text {S10TS28A }}$ expressing cells (Figs. 4b, S5), indicating PARPs and H3S10/S28 likely function in the same pathway with regards radioresistance.

To assess whether this sensitivity to phleomycin correlates with defective DSB repair, the induction and decay of $\gamma \mathrm{H} 2 \mathrm{AX}$ were assessed in $h 3 b^{-}$cells complemented with either Flag-H3b $\mathrm{b}^{\mathrm{WT}}$ or Flag-H3b $\mathrm{S}^{\mathrm{S} 10 \mathrm{~T}} \mathrm{~S} 28 \mathrm{~A}$. Whilst $h 3 b^{-}$cells expressing Flag-H3b ${ }^{\mathrm{S} 10 \mathrm{~T}}$ S28A exhibit a similar decay rate of $\gamma \mathrm{H} 2 \mathrm{AX}$ to those expressing Flag$\mathrm{H} 3 \mathrm{~b}^{\mathrm{WT}}$ following exposure to phleomycin it is delayed (Fig. 4c), indicating a requirement for $\mathrm{ADPr}$ at $\mathrm{H} 3 \mathrm{bS} 10$ and $\mathrm{S} 28$ to initiate repair of DNA damage. To gain a mechanistic insight into this phenotype, we additionally assessed whether similar to Adprtladependent $\mathrm{ADPr}^{35}, \mathrm{H} 3 \mathrm{bS} 10$ and S28 ADPr are required for the PBZ domain-dependent enrichment of $\mathrm{Ku}$ at DNA lesions in response to DNA DSBs. As described previously, whilst Ku80 is enriched in chromatin prepared from Ax2 cells exposed to phleomycin, it is reduced in the $h 3 b^{-}$strain (Fig. $4 d$ ). In contrast to Flag-H3b $\mathrm{b}^{\mathrm{WT}}$, the expression of Flag-H3b $\mathrm{b}^{\mathrm{S} 10 \mathrm{TS} 28 \mathrm{~A}}$ is unable to fully rescue this phenotype. Importantly, restriction-enzyme-mediated integration (REMI) of plasmid DNA into the genome (Fig. 4e), an event that is dependent on $\mathrm{NHEJ}^{35,37}$, is reduced in $h 3 b^{-}$cells. Moreover, whilst expression of Flag-H3b ${ }^{W T}$ can partially rescue this phenotype, Flag$\mathrm{H} 3 \mathrm{~b}^{\text {S10TS28A }}$ is unable to do so. Together, these data demonstrate the direct role of $\mathrm{H} 3 \mathrm{~b}$ ADPr at S10 and S28 in DNA repair and in particular, the initiation of the NHEJ pathway through promoting the recruitment and/or stabilisation of the heterodimer $\mathrm{Ku} 70 / \mathrm{Ku} 80$ at break sites.

Histone ADP-ribosylation and control of mitotic progression. Having established a role for $\mathrm{H} 3 \mathrm{~b}$ S10/S28 ADPr in DNA repair, we next wished to assess the relationship between this PTM with phosphorylation at these sites. Given that Ser-ADPr is able to disrupt phosphorylation at $\mathrm{H} 3 \mathrm{~S} 10$ in vitro ${ }^{32}$, we assessed whether these modifications exhibit opposing profiles in response to DNA damage. Consistent with previous observations, Flag- $\mathrm{H} 3 \mathrm{~b}^{\mathrm{wt}}$ is ADP-ribosylated in response to DNA DSBs (Fig. 5a). Importantly, however, this is accompanied by a concomitant reduction in the levels of $\mathrm{H} 3 \mathrm{~b}$ phosphorylation at S10, indicating a reciprocal relationship between the levels of $\mathrm{H} 3 \mathrm{bS} 10$ phosphorylation and $\mathrm{ADPr}$ in response to DNA damage.

Phosphorylation of histone H3S10 and S28 by the Aurora A and B kinases during mitosis has been implicated in chromatin condensation and mitotic progression in a number of organisms $s^{53}$. Given the reciprocal relationship between the levels of ADPr and phosphorylation at these sites, in addition to the availability of $\mathrm{H} 3 \mathrm{~b}$ S10 mutants that are ADPr-defective but phospho-competent, we assessed the consequences of defective ADPr on mitotic entry following DNA damage. To achieve this, cells were arrested in G2 and left either untreated, or exposed to phleomycin. Following removal of phleomycin and release from the G2 block, mitotic progression was assessed by monitoring synchronous cell doubling times. Consistent with the activation of a G2 checkpoint, a delay in mitotic entry is observed following exposure of $\mathrm{Ax} 2$ cells to phleomycin (Supplementary Fig. 6A). However, a more rapid resumption of cell cycle progression is apparent in the $h 3 b^{-}$strain relative to parental Ax2, indicating these cells enter mitosis prematurely following exposure to DNA DSBs (Fig. 5b and Supplementary Fig. 6B). Whilst expression of Flag- $\mathrm{H} 3 \mathrm{~b}^{\mathrm{wt}}$ is able to restore the ability of cells to restrain mitosis in response to DNA damage, Flag- $\mathrm{H} 3 \mathrm{~b}^{\mathrm{S} 10 \mathrm{TS} 28 \mathrm{~A}}$ expression is unable to do so and these cells progress through mitosis significantly quicker following a transient induction of DNA damage (Fig. 5b) with persistent $\gamma \mathrm{H} 2 \mathrm{AX}$ (Supplementary Fig. 7). Moreover, whilst PARPi similarly induces premature mitotic entry following DNA damage in AX2 or $h 3 b^{-}$cells expressing Flag-H3b ${ }^{w t}$, they do not exacerbate this phenotype in $h 3 b^{-}$cells expressing $\mathrm{H} 3 \mathrm{~b}^{\mathrm{S} 10 \mathrm{TS} 28 \mathrm{~A}}$ (Fig. 5b and Supplementary Fig. 6C), indicating that PARP activity and H3S10/S28 ADPr function in the same pathway with regards restraining mitotic entry in response to DSBs. A prediction of this model is that cells defective in ADPr will similarly enter mitosis prematurely in response to DNA damage. Consistent with this, we observe that cells disrupted in the principal Dictyostelium DDR PARPs Adprtla and Adprt2 (adprt1a-adprt2- cells) similarly enter mitosis prematurely following a transient exposure to DNA DSBs (Fig. 5c). Taken together, these results suggest that ADPr of $\mathrm{H} 3 \mathrm{~b}$ at $\mathrm{S} 10 / \mathrm{S} 28$ is required for an effective cell cycle checkpoint and that disruption of these events results in premature entry into mitosis with unresolved DNA damage.

Given the observed genome instability of $h 3 b^{-}$cells, we hypothesised that defective ADPr and mitotic entry with unresolved DSBs will contribute towards the increased genome instability observed in the $h 3 b^{-}$strain (Fig. 1a). To test this, we assessed nuclear morphology $48 \mathrm{~h}$ after a transient induction of DSBs in Ax2 cells or the $h 3 b^{-}$strain with or without expression

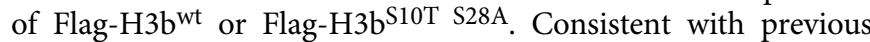
observations, we observe abnormal nuclear morphology in the $h 3 b^{-}$strain relative to AX2. Strikingly, whilst expression of Flag$\mathrm{H}_{3} \mathrm{~b}^{\text {wt }}$ is able to rescue this phenotype, Flag-H3b $310 \mathrm{~T}$ S28A is unable to do so (Fig. 5d). Given the premature mitotic entry of adprt $1 a^{-}$adprt $2^{-}$cells following DNA damage, we also assessed this phenotype in these cells. These cells similarly displayed abnormal nuclear morphology in response to DNA damage (Fig. 5e), further supporting a requirement for $\mathrm{H} 3 \mathrm{~b} \mathrm{ADPr}$ in genome integrity.

To further asses the consequences of deregulated H3b ADPr on mitotic progression, we performed live cell imaging in the $h 3 b^{-}$ strain expressing either Flag-H3b ${ }^{\text {wt }}$ or Flag-H3b ${ }^{\text {S10T S28A }}$ to assess the ability of cells to undergo cytokinesis. The $h 3 b^{-}$strain exhibits difficulties completing cytokinesis either in untreated cells, or cells exposed to phleomycin, a phenotype that is reflected in these cells displaying elevated levels of anaphase bridges (Fig. 6a and 
a

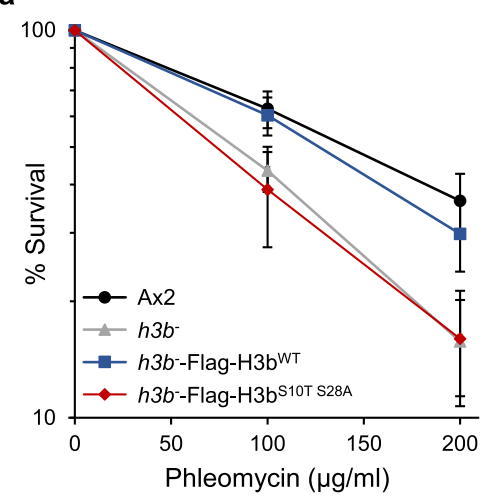

C
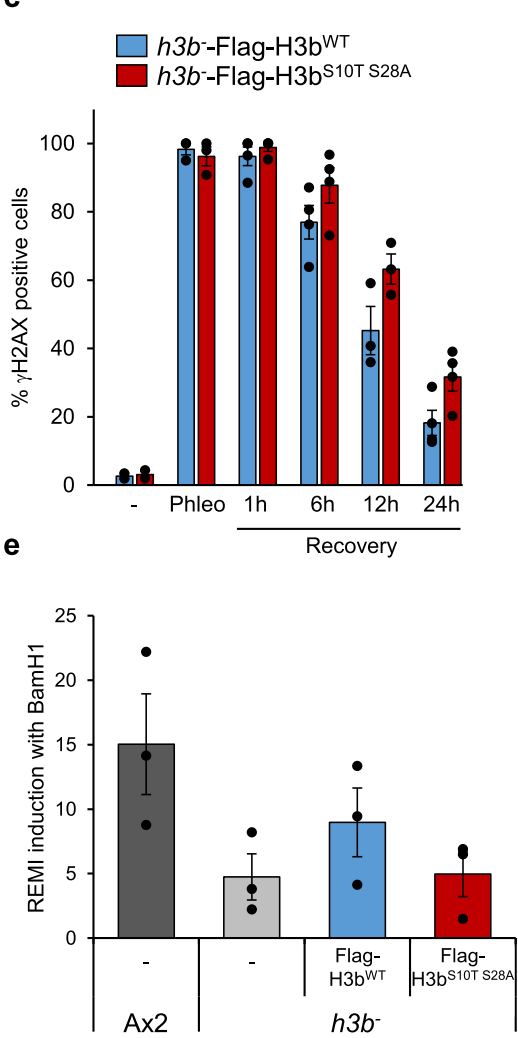

b

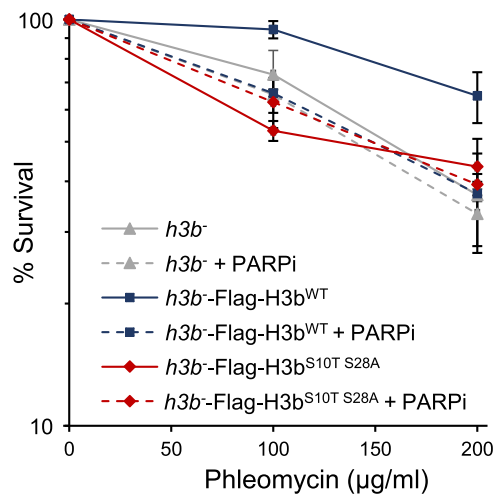

d

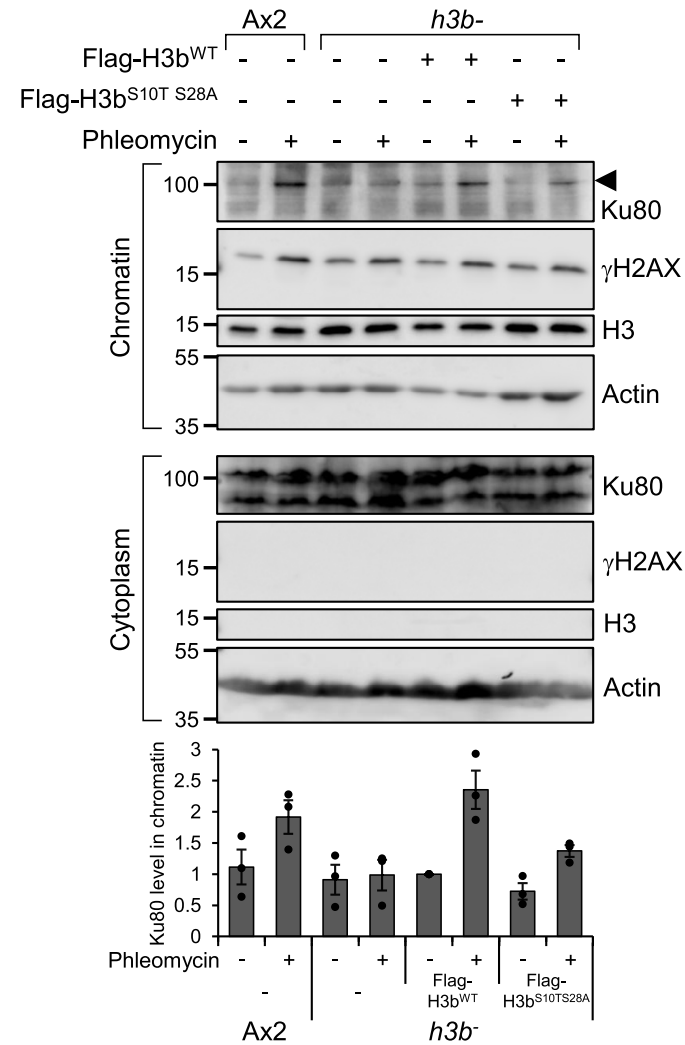

Fig. 4 H3b ADP-ribosylation is required for DSB repair. a Ax2 cells, or $h 3 b^{-}$cells expressing Flag-H3bWT or Flag-H3b ${ }^{S 10 T}$ S28A were exposed to phleomycin at the indicated concentrations and cell viability assessed by clonogenic survival assays (data represent seven biological repeats; error bars represent the SEM). $\mathbf{b} h 3 b^{-}$cells alone, or expressing Flag-H3bWT or Flag-H3bS10T S28A were exposed to phleomycin in the absence or presence of PARP inhibitors (olaparib; PARPi) as indicated and cell viability assessed by clonogenic survival assays (data represent three biological repeats; error bars represent the SEM). c $h 3 b^{-}$cells expressing Flag-H3bWT or Flag-H3bS10T S28A were left untreated ( - ) or exposed to phleomycin for $1 \mathrm{~h}$ (Phleo). Following removal of phleomycin, recovery of cells was analysed at the time points indicated. DNA damage was assessed by scoring $\gamma \mathrm{H} 2 \mathrm{AX}$ nuclei with $>5$ foci

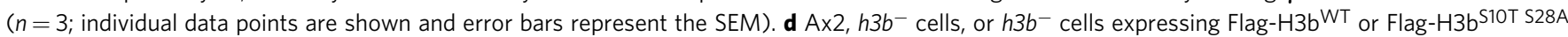
were left untreated or exposed to phleomycin as indicated. Cytoplasmic and chromatin fractions were prepared from cells and western blotting performed using the indicated antibodies (left panel). Molecular weight markers are indicated in kDa. Enrichment of Ku80 in chromatin fractions was quantified (lower panel; $n=3$; individual data points are shown and error bars represent the SEM). e Restriction-Enzyme Mediated Integration REMI of plasmid DNA was evaluated in Ax2, $h 3 b^{-}$cells, or $h 3 b^{-}$cells expressing Flag-H3bWT or Flag-H3bS10T S28A $(n=3$; individual data points are shown and error bars represent the SEM). Source data are provided in the Source Data file.

Supplementary Movie S1). This difference is apparent in untreated cells, suggesting some difficulties in completing cytokinesis independently of exogenous DNA damage. Nevertheless, whilst the levels of DNA damage-induced anaphase bridges are reduced by expression of Flag-H3b $b^{w t}$, this is not apparent in $h 3 b^{-}$cells

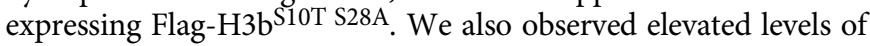
micronuclei in the $h 3 b^{-}$strain relative to Ax2 (Fig. $6 \mathrm{~b}$ and
Supplementary Movie S2). Whilst these phenotypes are partially complemented by the expression of Flag- $\mathrm{H} 3 \mathrm{~b}^{\mathrm{wt}}$, no such reduction in the number of micronuclei is observed on the expression of Flag- $\mathrm{H} 3 \mathrm{~b}^{\mathrm{S} 10 \mathrm{~T}} \mathrm{~S} 28 \mathrm{~A}$, indicating a requirement for $\mathrm{H} 3 \mathrm{~b}$ ADPr in suppressing micronuclei formation. Overall, these data indicate $\mathrm{ADPr}$ of $\mathrm{H} 3 \mathrm{~b}$ is required to regulate DNA repair and restrain mitotic entry in response to DNA damage. Furthermore, 
a

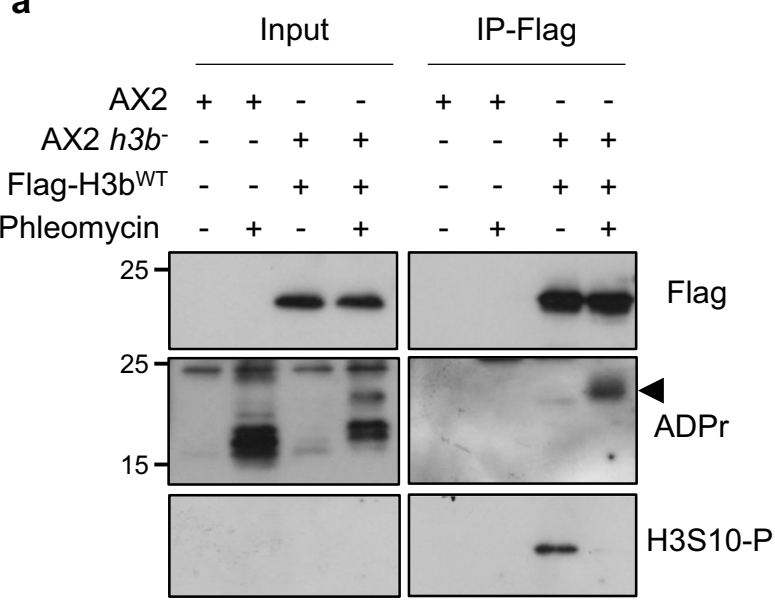

C

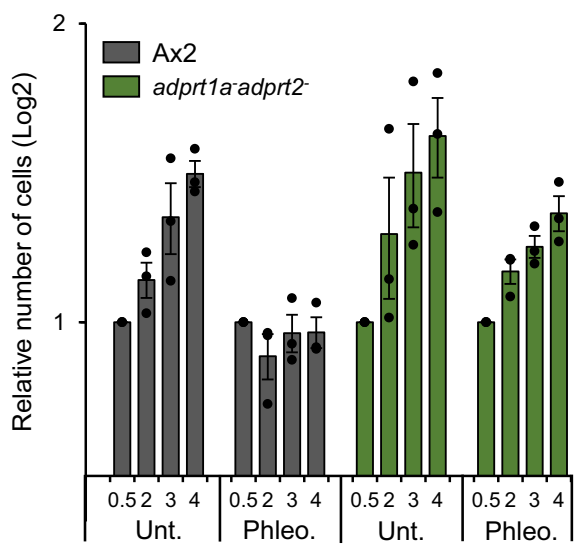

Post G2 Released (h)

b

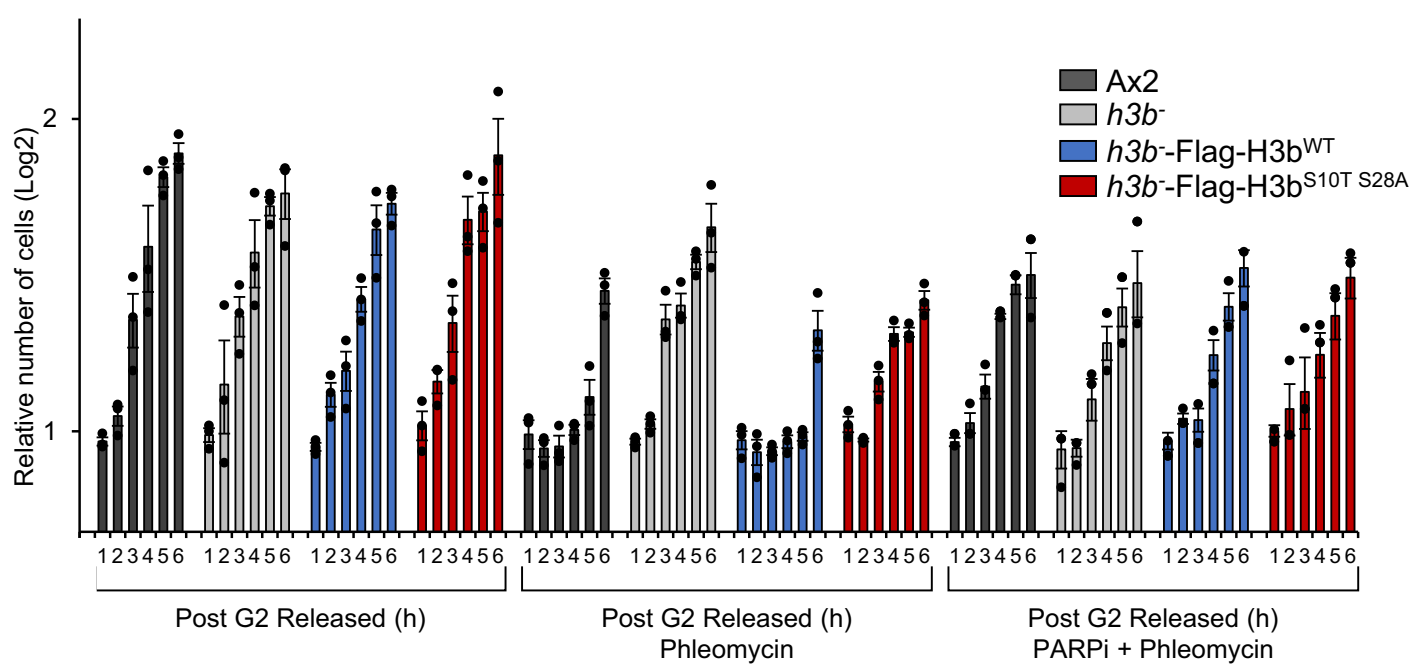

d

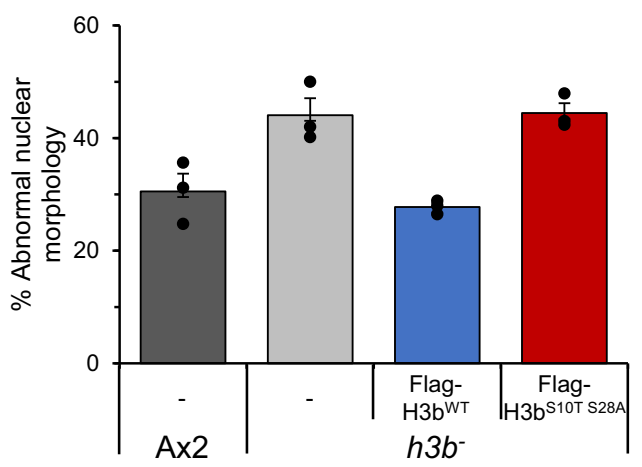

e

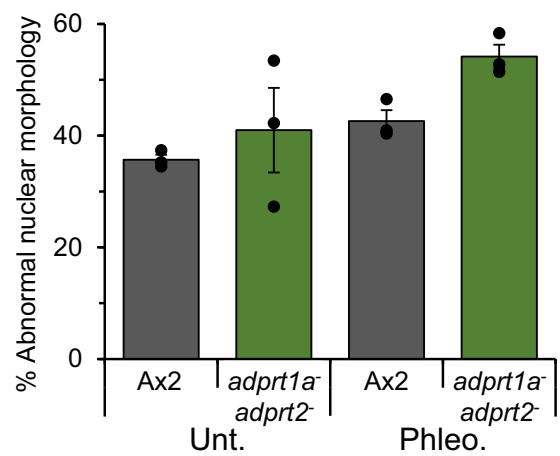

Fig. 5 H3b ADP-ribosylation is required to suppress premature mitotic entry with DNA damage. a Ax2 or $h 3 b^{-}$cells expressing Flag-H3bWT or Flag$\mathrm{H} 3 \mathrm{~b}^{\mathrm{S} 10 \mathrm{TS} 28 \mathrm{~A}}$ were left untreated or exposed to phleomycin as indicated. Western blotting of Flag-immunoprecipitates was performed using the indicated antibodies. Molecular weight markers are indicated in $\mathrm{kDa}$. b Ax2, $h 3 b^{-}$cells, or $h 3 b^{-}$cells expressing Flag-H3bWT or Flag-H3b $10 \mathrm{~T}$ S28A were arrested in G2 and following treatment or not with phleomycin in the absence or presence of olaparib, released into fresh media to allow resumption of the cell cycle. Progression through mitosis was monitored by assessing cell number at times following release from G2. c Ax2 and adprt7a- adprt2- cells were arrested in G2 and following treatment or not with phleomycin assessed for mitotic entry as described in (b). $\mathbf{d} \mathrm{Ax} 2, h 3 b^{-}$cells and $h 3 b^{-}$cells expressing Flag-H3bWT or Flag-H3b 10 TS28A were treated with a transient exposure to phleomycin for one $\mathrm{h}$ and after $48 \mathrm{~h}$ of recovery abnormal nuclear morphology assessed by microscopy. e Chromosome fragmentation in Ax2 or adprt1a-adprt2- cells was assessed as in (d). All graphs represent the average of 3 independent experiments. Individual data points are shown and error bars represent the SEM. Source data are provided in the Source Data file. 
a

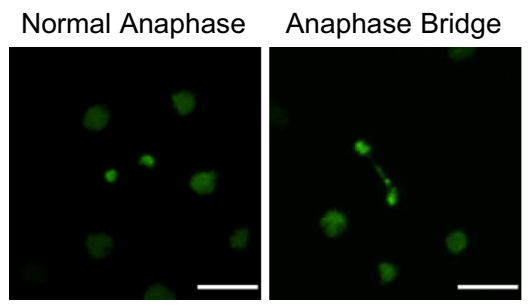

b

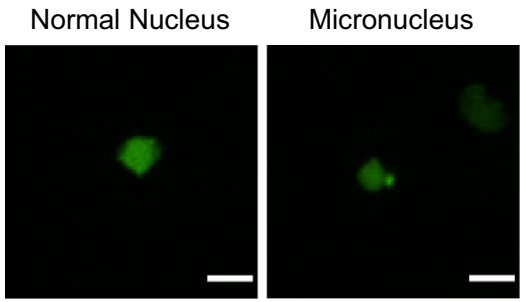

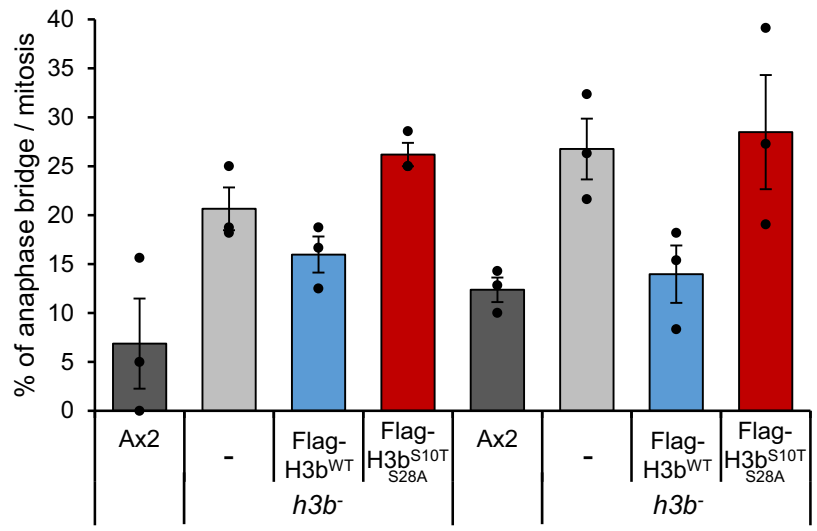

Unt.

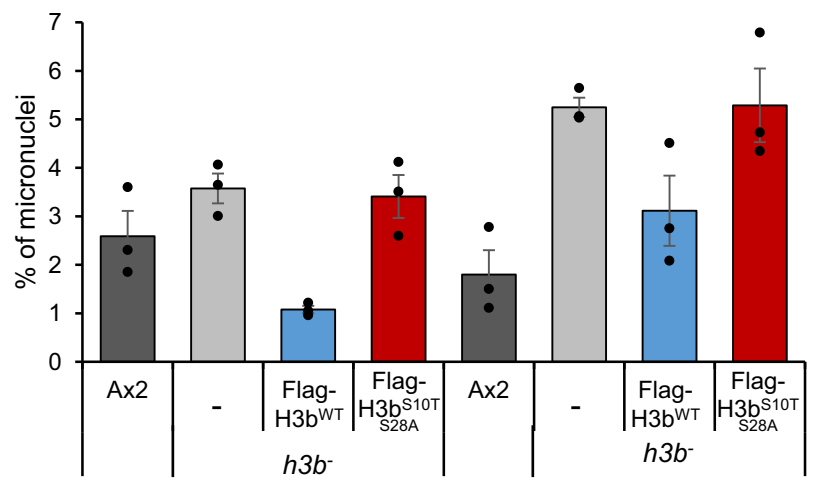

Unt.

Fig. 6 H3b ADP-ribosylation is required for faithful completion of cytokinesis. a Ax2, $h 3 b^{-}$cells, or $h 3 b^{-}$cells expressing Flag-H3bWT or Flag-H3bS10T S28A expressing GFP-H2B were assessed for anaphase bridges during cytokinesis in either untreated cells, or cells exposed to phleomycin. A representative image of an anaphase bridge is illustrated (left panel) and quantification of data from three independent experiments (right panel). Scale bars: $10 \mu \mathrm{m}$. b Ax2, $h 3 b^{-}$cells, or $h 3 b^{-}$

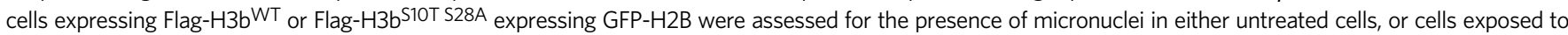
phleomycin. A representative image of a micronucleus is illustrated (left panel) and quantification of data from 3 independent experiments (right panel). Scale bars: $5 \mu \mathrm{m}$. Source data are provided in the Source Data file.

they also implicate $\mathrm{H} 3 \mathrm{~b} \mathrm{ADPr}$ in the faithful completion of cytokinesis to maintain genome instability.

\section{Discussion}

The role of PARPs in regulating DNA repair is well established. However, despite DNA damage-induced ADPr being described decades ago, the mechanistic basis of how site-specific ADPr events regulate DNA repair and genome stability remains elusive. This, in part, has been due to the lack of appropriate technologies to identify ADPr events induced in response to different types of DNA damage. Whilst recent developments in MS approaches have resolved this issue ${ }^{21-25}$, understanding the functional significance of these modifications remains a challenge, particularly in the context of histones. The identification that serine is the major target for ADPr in response to genotoxic stress and that this modification can influence other PTMs on histone tails introduces an added level of complexity to the system. This is compounded by difficulties in manipulating multi-copy histone genes in vertebrates, or the limited conservation of PARPs in model organisms where this is possible. Dictyostelium is an ideal experimental platform to bridge this gap due to the high degree of vertebrate DNA repair pathway conservation in this organism, including PARPs, and the ability to manipulate single copy histone genes in this system. Here we exploit these characteristics to assess the role of histone ADPr in DNA repair. Importantly, we develop a separation of function mutation strategy that allows us to assess the role of Ser-ADPr in DNA repair and cell cycle progression whilst maintaining the phosphorylation status of these sites.

In vertebrates, $\mathrm{ADPr}$ was originally believed to be confined to glutamate and aspartate, and we have similarly been able to identify ADPr at these sites in Dictyostelium, most notably at H2BE18/1950. However, ADPr of histones at serine has emerged as a major event in response to genotoxic stress ${ }^{23,31}$. The recent identification that this is predominantly mono-ADPr catalysed by PARP1/HPF1 that can be reversed by ADP-ribosylhydrolase 3 (ARH3) has more fully defined the readers and writers of the histone ADPr code $e^{24,30,54}$. Using an antibody that recognises HPF1-dependent serine-ADPr ${ }^{34}$ coupled with mutation strategies, we identify that Dictyostelium proteins, including histones, are also ADP-ribosylated on serine (Figs. 2,3). These observations indicate Ser-ADPr is conserved in Dictyostelium suggesting it is widely conserved in eukaryotes. HPF1 is critical in converting the catalytic activity of PARP1 and PARP2 from Asp/Glu to serine ${ }^{24,30}$. Intriguingly, however, we have been unable to identify an HPF1 homologue in the Dictyostelium genome. This might indicate the presence of an unidentified factor in Dictyostelium that acts analogous to HPF1 to convert the catalytic activity of the principal DDR PARPs (Adprt1a/Adprt2) to modify serine. Alternatively, the findings that HPF1 and PARP1 act together to form a full active site for the enzyme ${ }^{55,56}$, taken together with our observations that Adprtla catalyses mono-ADPr in vitro ${ }^{50}$, raise the possibility that Dictyostelium PARPs might contain an 
intrinsic Ser-ADPr activity, circumventing the need for HPF1. Distinguishing these possibilities will provide insights into the nature of PARP catalytic specificity in a number of organisms.

The identification of Ser-ADPr introduces a further level of regulation through influencing PTMs at adjacent amino acids, or at serine directly. This is a particularly attractive hypothesis in the context of N-terminal histone tails where the high abundance of multiple PTM sites will allow ADPr to impact on a wide variety of modifications. Whilst this concept was originally proposed in the context of Ser-ADPr ${ }^{32,33}$, it has recently been extended to glutamate $\mathrm{ADPr}^{26}$. Therefore, different patterns of ADPr may impact on a wide variety of PTMs, introducing additional flexibility in the histone code. The mutually exclusive modification of serine by ADPr or phosphorylation ${ }^{32,34}$ taken together with the widespread use of serine phosphorylation to regulate a large number of pathways, makes it likely the interplay between these opposing PTMs will impact on a variety of processes. However, the analysis of the relationships is challenging. Commonly used mutation strategies that disrupt ADPr will also interfere with serine phosphorylation making it difficult to disentangle the functional significance of these opposing PTMs. Phosphorylation events may also be critical for cell viability, a possibility that is highlighted by a large number of DNA damage-induced SerADPr sites also being targets for the mitotic kinases Aurora A and $\mathrm{B}^{25,52}$. Whilst generating phospho-mimic mutations may address these problems, these strategies employ acidic amino acids (e.g. Asp) that are also ADP-ribosylated. By exploiting the inability of threonine to be ADPr we have developed a mutation strategy that allows the disruption of site-specific ADPr events whilst retaining the ability to maintain phosphorylation at these sites. Although the ability to phosphorylate S-T sites may be context dependent, we predict this strategy will be applicable to other ADPr sites in histones and other targets for Ser-ADPr. The conservation of the major histone PTMs in Dictyostelium ${ }^{45-49}$, together with the ability to generate site-specific mutations in histones, makes this an attractive system to study these possibilities.

Our ability to manipulate histone genes in Dictyostelium has provided unique insights into the relationship between histone ADPr and DNA repair. The deletion of $h 3 b$ is not lethal to Dictyostelium cells. Strikingly, however, these cells display chromosomal instability, a phenotype that is reflected in radiosensitivity and a delay in resolving DNA DSBs. Our data clearly indicate a requirement for $\mathrm{S} 10 / \mathrm{S} 28 \mathrm{ADPr}$ in supressing these phenotypes (Fig. 4), as opposed to a more general requirement for $\mathrm{H} 3 \mathrm{~b}$ in these processes. Mechanistically, our data point to a link between $\mathrm{H} 3 \mathrm{~b}$ ADPr and accumulation of $\mathrm{Ku}$ at DNA lesions. It is well established that accumulation of DNA repair and chromatin remodelling factors is achieved in a PARP-dependent manner though ADP-ribose binding motifs in these proteins ${ }^{1}$. Our previous work identified this mechanism is conserved in Dictyostelium with the PBZ domain in Ku70 being required to assemble DNA repair factors at damage sites to facilitate $\mathrm{NHEJ}^{35}$. However, the substrates modified at sites of DNA damage that enable the accumulation of repair factors at DNA damage are unknown. Here we resolve this question by illustrating that $\mathrm{ADPr}$ of $\mathrm{H} 3 \mathrm{~b}$ at $\mathrm{S} 10 / \mathrm{S} 28$ is required for the accumulation of $\mathrm{Ku}$ at DSBs. Intriguingly, PBZ domains interact with poly-ADPr, whilst Ser-ADPr is predominantly mono-ADPr. Whether the requirement for both a PBZ domain and $\mathrm{H} 3 \mathrm{~b}$ Ser-ADPr to assemble $\mathrm{Ku}$ at breaks represents poly-ADPr of $\mathrm{H} 3 \mathrm{bS} 10 / 28$ or other sites/factors in Dictyostelium is unknown. Additionally, it is possible that this indicates a direct link between H3b ADPr and recruitment of repair factors such as $\mathrm{Ku}$ to DNA lesions. However, a wide variety of histone PTMs, including methylation, acetylation and ubiquitylation are required for efficient resolution of DSBs. Therefore, another non-mutually exclusive possibility is that S10/S28
ADPr impacts on other histone PTMs required for DSB repair either directly, or by influencing the accumulation of histone modifying activities at DSBs. The conservation of key human repair and chromatin modifications in Dictyostelium, along with the ability to manipulate single copy histone genes in this experimental system, suggests this organism will be an important model to investigate these possibilities.

Our mutation strategy that retains phosphorylation at $\mathrm{H} 3 \mathrm{~S} 10$ while disrupting ADPr reveals a critical role for ADPr of $\mathrm{H} 3 \mathrm{bS} 10$ / S28 to restrain mitotic entry in response to DNA damage. It is possible that similar to recruiting repair factors to DSBs, S10/S28 ADPr promotes the accumulation and activation of checkpoint proteins to damage sites. In this regard, the PAR-binding PBZmodule of CHFR is required for a functional antephase checkpoint that restrains mitotic entry in response to a variety of stresses $^{57}$. However, it is also possible ADPr has a wider impact on cell cycle progression in response to DNA damage. Phosphorylation of S10 and S28 by Aurora kinases is pivotal in regulating various aspects of mitosis including chromosome condensation $^{58-60}$ and initiating a phospho-methyl switch that causes displacement of HP1 and PRC1 from chromatin ${ }^{61,62}$. Our data indicate a reciprocal relationship in the levels of $\mathrm{H} 3 \mathrm{bS} 10$ ADPr and phosphorylation following DNA damage. This may reflect DNA damage-induced ADPr and loss of the mitotic cell population by activation of the G2/M checkpoint. However, given Ser-ADPr can directly inhibit $\mathrm{ADPr}^{32}$, it is also possible that ADPr counteracts S10/S28 phosphorylation to inhibit normal cell cycle progression and mitosis. ADPr of S10/S28 may also interfere with other PTMs at adjacent sites that are required for cell cycle progression, such as T3 phosphorylation that promotes the enrichment of CPC at centromeres that in turn phosphorylates H3S10/S28 to promote mitotic progression ${ }^{63,64}$. Indeed, many of the sites ADP-ribosylated in response to DNA damage are targets for mitotic kinases and Aurora B activity is inhibited in response to DNA damage through $\mathrm{ADPr}^{65}$. This might suggest a wider role of $\mathrm{ADPr}$ in regulating mitotic progression through a variety of mechanisms. In support of this model, we observe that H3bADPr mutants or adprt1a-adprt2- cells exhibit difficulties undergoing cytokinesis, even in the absence of exogenous DNA damage (Figs. 5 and 6). However, these phenotypes could also be explained by an accumulation of DNA damage in DNA repair defective strains. For example, it has been known for some time that PARPs and ADPr function in regulating mitosis ${ }^{66}$. Cells defective in the PARP1 and/or PARP2 exhibit a variety of mitotic defects including centrosome amplification, ultra-fine anaphase bridges and loss of spindle assembly checkpoint integrity ${ }^{66-71}$. However, these phenotypes can often be caused by defective replication-associated repair, a mechanism that both PARP1 and PARP2 regulate ${ }^{5,16-19}$. As such, defective NHEJ in H3b-ADPr mutants may also result accumulation of endogenous DNA damage that subsequently results in difficulties during cytokinesis. Therefore, we are currently unable to distinguish whether the genome instability in $\mathrm{H} 3 \mathrm{~b}-\mathrm{ADPr}$ mutants is a consequence of defective cytokinesis, DNA repair, or both. However, our findings that $\mathrm{H} 3 \mathrm{~b}^{\mathrm{S} 10 \mathrm{TS} 28 \mathrm{~A}}$ mutants or adprt1a/adprt2 cells display premature entry into mitosis in response to DNA damage provide a clear link between DNA damage responsive PARPs, histone $\mathrm{ADPr}$ and regulation of mitotic entry in response to DNA damage.

In summary, we observe that the histone variant $\mathrm{H} 3 \mathrm{~b}$ is required for efficient DNA repair and genome stability in Dictyostelium. Through identifying that Ser-ADPr is conserved in this organism, we identify that the requirement for $\mathrm{H} 3 \mathrm{~b}$ in DSB repair is through ADPr at S10 and S28 and define the mechanistic basis of this regulation by illustrating it promotes the PARPdependent assembly of NHEJ factors at DSBs. Critically, we also 
identify that $\mathrm{ADPr}$ of $\mathrm{H} 3 \mathrm{~S} 10 / \mathrm{S} 28$ is required to restrain mitotic entry in the presence of DNA damage indicating a critical role for $\mathrm{ADPr}$ in regulating cell cycle progression in response to DNA damage.

\section{Methods}

Cell culture, DNA transfection, establishment of stable cell lines. Dictyostelium Ax2 cells were grown according to standard procedures, either axenically with HL5 media (Formedium HLB0101; 20\% Glucose) or on SM agar plates in association with Klebsiella aerogenes at $22{ }^{\circ} \mathrm{C}$. Exponential growing cells are defined as a concentration of $2-6 \times 10^{6} \mathrm{cells} / \mathrm{ml}$.

The $h 3 b^{-}$, adprt1a- adprt2- $k u 80^{-}$and $\mathrm{exol}^{-}$strains have been previously described $35,37,38,42,45$. The Flag-Rad51 expression plasmid has been previously described $^{42}$

$\mathrm{H} 3 \mathrm{~b}$ cDNA was cloned into the plasmid pDM304-Cter 3x-Flag using the following primers (forward: GCAGATCTAAAATGGCCCGTACAAAACAAAC CG; reverse: GCACTAGTAGCACGTTCACCTCTGATACGTCTGG).

Mutagenesis was performed using QuikChange XL Site-Directed Mutagenesis $\mathrm{Kit}^{\oplus}$ and appropriate primers as followed: H3b S28A (forward: CTTCTCAAAAA GCTTTTCCATCAACCCAAGG; reverse: CCTTGGGTTGATGGAAAAGCTTTT TGAGAAG), H3b S10A (forward: CAAACCGCTAGAAAAGCAACTGGTGCT AAAGTACC; reverse: GGTACTTTAGCACCAGTTGCTTTTCTAGCGGTTTG), H3b S10T (forward: CAAACCGCTAGAAAAACAACTGGTGCTAAAGTACC; reverse GGTACTTTAGCACCAGTTGTTTTTCTAGCGGTTTG).

Transfection was performed as previously described ${ }^{43}$, using the GenePulser $\mathrm{Xcell}^{\oplus}\left(\right.$ Biorad $\left.^{\oplus}\right)$. Transfected cell lines were selected with the antibiotic G418 $(10 \mu \mathrm{g} / \mathrm{ml})$ for at least 7 days to establish stable cell lines. Stable cell lines were cultivated with media complemented with G418 antibiotic $(10 \mu \mathrm{g} / \mathrm{ml})$.

Acid extraction. Acid extraction was performed as previously described ${ }^{50}$. Briefly, exponential growing cells were collected and resuspended at a concentration of $1 \times 10^{7}$ cells $/ \mathrm{ml}$ and either untreated or exposed to $1 \mathrm{~h}$ of phleomycin $(300 \mu \mathrm{g} / \mathrm{ml})$. Cells were pelleted, washed twice with cold KK2, and resuspend in lysis buffer (50 mM Tris $\mathrm{HCl} \mathrm{pH} \mathrm{8.0,10} \mathrm{mM} \mathrm{NaCl,} 3 \mathrm{mM} \mathrm{MgCl}_{2}, 3 \mathrm{mM} \mathrm{CaCl}_{2}, 0.5 \mathrm{M}$ Sorbitol, $0.6 \%$ Triton X-100; completed with proteases (Complete cocktail-Roche ${ }^{\circ}$ ), phosphatases $\left(\mathrm{Na}_{3} \mathrm{VO}_{4}\right.$ and $\left.\mathrm{NaF}\right)$, PARP $(50 \mu \mathrm{M}$ Benzamide $)$ and PARG $(200 \mu \mathrm{M}$ DEA $)$ inhibitors) at a concentration of $1 \times 10^{8}$ cells $/ \mathrm{ml}$, incubated with rotation at $4{ }^{\circ} \mathrm{C}$ for $10 \mathrm{~min}$, and the nuclei pelleted by centrifugation at $2300 \mathrm{~g}$ for $5 \mathrm{~min}$. Extracted nuclei were resuspended/washed in nuclear extraction buffer containing $4 \mathrm{M}$ urea, and $2 \% \beta$-mercaptoethanol, and pelleted again by centrifuging at $2300 \mathrm{~g}$ for $5 \mathrm{~min}$. Isolated nuclei were then resuspended in $0.4 \mathrm{~N} \mathrm{HCl}$ at a density of $2 \times 10^{8}$ nuclei/ $\mathrm{ml}$, and mixed by rotation at $4^{\circ} \mathrm{C}$ for $1 \mathrm{~h}$. Acid extracted histones were harvested by centrifugation at $16,000 \mathrm{~g}$, and the supernatant precipitated by addition of 6.5 volumes of cold acetone, incubating at $-20{ }^{\circ} \mathrm{C}$ over-night, and centrifuging at $16,000 \mathrm{~g}$ for $15 \mathrm{~min}$ at $4^{\circ} \mathrm{C}$. The pellet was washed twice with cold acetone, airdried, and resuspended first in water at $37^{\circ} \mathrm{C}$ for $15 \mathrm{~min}$, then SDS buffer $(10 \mathrm{mM}$ Tris $\mathrm{pH} 6.8,5 \%$ glycerol, $1 \%$ SDS, $1 \% \beta$-Mercaptoethanol) was added vol/vol and boiled at $95^{\circ} \mathrm{C}$ for $5 \mathrm{~min}$.

Biochemical fractionation. Cells were treated and collected for acid extraction. Cell pellets were lysed $5 \mathrm{~min}$ at $4{ }^{\circ} \mathrm{C}$ with buffer A $(10 \mathrm{mM}$ Tris $\mathrm{HCl} \mathrm{pH} 8.0,10 \mathrm{mM}$ $\mathrm{KCl}, 1.5 \mathrm{mM} \mathrm{MgCl}, 3 \mathrm{mM} \mathrm{CaCl}, 0.34 \mathrm{M}$ sucrose, $10 \%$ glycerol, $0.5 \%$ Triton X100; completed with proteases (Complete cocktail-Roche ${ }^{6}$ ), phosphatases (Na3VO4 and NaF), PARP (50 $\mu \mathrm{M}$ Benzamide) and PARG (200 $\mu \mathrm{M} \mathrm{DEA})$ inhibitors) at a concentration of $1 \times 10^{8}$ cells $/ \mathrm{ml}$. Cell lysis lysates were centrifuged for $5 \mathrm{~min}$ at $1700 \mathrm{~g}, 4^{\circ} \mathrm{C}$. Supernatants (cytoplasm) were collected, and the nuclear pellet was washed once with lysis buffer A (including inhibitors). The nuclear pellets were resuspended in no-salt buffer ( $3 \mathrm{mM}$ EDTA, $0.2 \mathrm{mM}$ EGTA, inhibitors as in lysis buffer) and hypotonic lysis left for $30 \mathrm{~min}$ at $4^{\circ} \mathrm{C}$, with occasional vortexing. Samples were centrifuged for $5 \mathrm{~min}$ at $8000 \mathrm{~g}, 4^{\circ} \mathrm{C}$, the supernatants were removed, and the chromatin pellets were washed once with no-salt buffer. The final pellets were resuspended in SDS buffer (10mMTris $1 \mathrm{M} \mathrm{pH} \mathrm{6.8,5 \%}$ glycerol, $1 \%$ SDS, $1 \% \beta$-Mercaptoethanol at a concentration of $1 \times 10^{8} \mathrm{cells} / \mathrm{ml}$, and boiled at $95^{\circ} \mathrm{C}$ for $5 \mathrm{~min}$ and were called the chromatin fraction.

Immunoprecipitation. For asynchronous cells, immunoprecipitations were performed on chromatin fractions prepared as described above, while for mitotic cells, they were performed on whole-cell extract. Chromatin pellets or cell pellets were resuspended in $4 \%$ SDS buffer (4\% SDS, $100 \mathrm{mM}$ Tris $\mathrm{HCl}$ pH6.8) and boiled at $95^{\circ} \mathrm{C}$ for 10 min to denature the proteins. An aliquot was taken as the input. The remaining samples were diluted 10 times in IP buffer $(50 \mathrm{mM}$ Tris $\mathrm{HCl} \mathrm{pH} 8$, $200 \mathrm{mM}$ NaCl, $1 \mathrm{mM}$ EDTA, $1 \mathrm{mM}$ DTT, $10 \%$ glycerol, $1 \%$ Triton X-100 + inhibitors). $50 \mu \mathrm{l}$ of anti-Flag-M2 affinity gel (Sigma ${ }^{\oplus}$, A2220) were used per immunoprecipitation. Prior adding sample onto the beads, they were washed twice with IP buffer. Diluted samples were incubated with the beads for $2 \mathrm{~h}$ at $4{ }^{\circ} \mathrm{C}$ on a rotating wheel. After centrifugation $(500 \mathrm{~g}, 2 \mathrm{~min})$, the beads were washed three times with IP buffer and once with TBS buffer (50 mM Tris-HCl pH 7.4, $150 \mathrm{mM}$ $\mathrm{NaCl}$ ). Elution through competition using Flag peptide (Sigma ${ }^{\circ}$ F4799) was performed: an equal volume of $100 \mathrm{ng} / \mu \mathrm{l}$ Flag-peptide in TBS buffer was added to the beads, the samples were vortexed gently for $5 \mathrm{~min}$ and centrifuged to collect the supernatant. This was repeated a second time. The eluates were diluted in SDS buffer and boiled before immunoblot analysis.

Affinity purification of ADPr proteins. Cells were pelleted, washed with cold $\mathrm{KK} 2$, and resuspended in lysis buffer $(50 \mathrm{mM}$ Tris $\mathrm{HCl} \mathrm{pH} \mathrm{8.0,10} \mathrm{mM} \mathrm{NaCl}, 3 \mathrm{mM}$ $\mathrm{MgCl}_{2}, 3 \mathrm{mM} \mathrm{CaCl}, 0.5 \mathrm{M}$ Sorbitol, $0.6 \%$ Triton X-100; with protease inhibitors (Complete cocktail-Roche $\left.{ }^{\circ}\right)$, PARP $(50 \mu \mathrm{M}$ Benzamide) and PARG (200 $\mu \mathrm{M}$ DEA) inhibitors) at a concentration of $100 \times 10^{6} \mathrm{cells} / \mathrm{ml}$, incubated with rotation at $4{ }^{\circ} \mathrm{C}$ for $10 \mathrm{~min}$, and the nuclei pelleted by centrifugation at $2300 \mathrm{~g}$ for $5 \mathrm{~min}$. Extracted nuclei were resuspended/washed with the same buffer. $10 \%$ of the nuclei were collected as the Input. The rest of the nuclei were lysed with $\mathrm{GnHCl}$ buffer $(6 \mathrm{M}$ Guanidine hydrochloride, $50 \mathrm{mM}$ TrisPh8.5) for $30 \mathrm{~min}$ with rotation at $4{ }^{\circ} \mathrm{C}$ Then, the samples were diluted 10 times in IP buffer $(50 \mathrm{mM}$ Tris $\mathrm{HCl} \mathrm{pH8}$, $200 \mathrm{mM} \mathrm{NaCl}, 1 \mathrm{mM}$ EDTA, $1 \mathrm{mM}$ DTT, 10\% glycerol, 1\% Triton X-100 + inhibitors). $20 \mu$ of prior washed Dynabead ${ }^{\circledR}$-Protein G (Invitrogen ${ }^{\circledR}$ ) was added for $1 \mathrm{~h}$. Meanwhile, $3 \mu \mathrm{g}$ of PAN-ADPr reagent (Merk MABE1016) was incubated with $30 \mu \mathrm{l}$ of Dynabead ${ }^{\circ}$-Protein G (Invitrogen ${ }^{\star}$ ) for $1 \mathrm{~h}$ in $0.01 \%$ Tween-20 in KK2. Pre-cleared samples were incubated with the conjugated beads at $4{ }^{\circ} \mathrm{C}$ on a rotating wheel. The beads were washed for $5 \mathrm{~min}$, with the following buffers: W1 (Tris pH8 $10 \mathrm{mM}, \mathrm{KCl} 150 \mathrm{mM}$, NP40 0.5\%, EDTA $1 \mathrm{mM}$ ), W2 (Tris pH8 $10 \mathrm{mM}$, $\mathrm{NaCl} 200 \mathrm{mM}$, TritonX100 0.5\%) W3 (Tris pH8 $10 \mathrm{mM}, \mathrm{NaCl} 400 \mathrm{mM}$, TritonX100 0.5\%), W4 (Tris pH8 $10 \mathrm{mM}, \mathrm{NaCl} 500 \mathrm{mM}$, TritonX100 0.5\%), W5 (Tris pH8 $10 \mathrm{mM}, \mathrm{LiCl} 250 \mathrm{mM}$, NP40 0.5\%, EDTA $1 \mathrm{mM}$ ) and W6 (Tris pH8 $10 \mathrm{mM}$, EDTA $1 \mathrm{mM}$ ). Elution was performed by boiling samples in SDS buffer. Samples were analysed by immunoblotting.

Cell synchronisation. Cells were arrested in G2 phase as previously described ${ }^{40}$. Briefly, exponentially growing cells were seeded at a dilution of $1 \times 10^{6} \mathrm{cells} / \mathrm{ml}$ and incubated in shaking suspension $(220 \mathrm{rpm})$ at $9.5^{\circ} \mathrm{C}$ over-night. Subsequently, cells were released from this block by raising the temperature of cultures to $22^{\circ} \mathrm{C}$ within $30 \mathrm{~s}$ and incubating cells in shaking suspension at $22^{\circ} \mathrm{C}$.

To enrich cell population in mitosis, cells were first arrested in G2, then released in presence of $10 \mu \mathrm{g} / \mathrm{ml}$ of nocodazole (Cayman Chemical Company ${ }^{6}$ ). For biochemical study, cells were collected 4 to $6 \mathrm{~h}$ after the release.

To assess entry in mitosis following DNA damage, cells were arrested in G2 as above and treated with $200 \mu \mathrm{g} / \mathrm{ml}$ of phleomycin for $1 \mathrm{~h}$, then washed twice with $9.5^{\circ} \mathrm{C}$ KK2 (centrifugation at $10^{\circ} \mathrm{C}$ ) and released from cell cycle arrest by adding $22^{\circ} \mathrm{C}$ HL5 media.

To monitor cell proliferation after G2 release, cells were plated on a 8-well slide (Starsted ${ }^{\circ}$ ) at $22^{\circ} \mathrm{C}$ and recorded for approximately $10 \mathrm{~h}$ with a microscope Zeiss IX71 (10X objective, brightfield, 1 picture/min). Using the software Image ${ }^{\oplus}$, cell number was manually counted on pictures of the appropriate time points and normalised with the earlier time point.

Sensitivity assays. Sensitivity assays were performed as described previously 35 Exponentially growing Dictyostelium were diluted at a concentration of $1 \times 10^{6}$ cells/ml in HL5 media and treated for one $\mathrm{h}$ with phleomycin at the indicated concentrations. Afterwards cells were diluted in KK2, 250 cells were mixed with $K$. aerogenes, and spread onto $140 \mathrm{~mm}$ SM agar plates. The plates were incubated at $22^{\circ} \mathrm{C}$. After 4 to 7 days, Dictyostelium plaque formation were counted and cell survival calculated by normalising with the number of colonies without phleomycin treatment. Graphs of data were constructed using Excel 2016.

PARP inhibitors. Two PARPs inhibitors were used in this study Olaparib (LKT laboratories ; stock solution $10 \mathrm{mg} / \mathrm{ml}$ in DMSO, experimental concentration $230 \mu \mathrm{M}$ ) and Benzamide (Sigma ; freshly prepared stock of $500 \mathrm{mM}$ in $70 \%$ ethanol, experimental concentration $2.5 \mathrm{mM}$ ). PARP inhibitors were added onehour prior to phleomycin treatment and during application of DNA damage.

Restriction-enzyme-mediated integration of plasmid DNA into the Dictyostelium genome. REMI was performed essentially as previously described ${ }^{37}$. To generate vectors bearing restriction-enzyme sites at DNA ends, the plasmid pHygTm(plus)/pG7 (containing a Hygromycin cassette) was cut with BamH1 (NEB), treated with calf intestinal alkaline phosphatase (NEB) and purified on PCR clean up columns (QIAGEN $\left.{ }^{\circ}\right) .4 .5 \times 10^{6}$ cells per condition were transfected with $2 \mu \mathrm{g}$ of BamH1-linearised construct with or without 20 units of the restrictionenzyme BamH1 (NEB). Electroporated cells were spread on four $140 \mathrm{~mm}$ plates with axenic HL5 media. $24 \mathrm{~h}$ after transfection, hygromycin $(35 \mu \mathrm{g} / \mathrm{ml})$ was added for 5 days. Afterwards, plates were washed with KK2, fixed with $3.7 \%$ formaldehyde and stained with Crystal Violet solution. Colonies were counted and REMI induction calculated as the ratio of colony numbers with and without BamH1. Graphs of data were constructed using Excel 2016.

Immunoblot analysis. Proteins were resolved by Mini Gel SDS-PAGE (Biorad ${ }^{\star}$ system) and transferred to PVDF membrane (Immobilon- $\mathrm{P}^{\oplus}$ - Millipore ${ }^{\oplus}$ ) according to standard procedures. Blocking and antibody incubations were 
performed in TBS $-0.2 \%$ Tween- $20^{\circ} 5 \%$ milk $\left(\right.$ Marvel $\left.^{\oplus}\right)$. The following primary antibodies were used: anti-Ku80, $(1: 1000)^{38}$, anti-actin (1:5000, Santa-Cruz ${ }^{\oplus}$ sc- $^{-}$ 1615), anti-H2AX-P (1:1000, Abcam ${ }^{\circledast}$ ab11174), anti-H3 (1:2000, Abcam ${ }^{\odot}$ ab12079), anti-flag (1:2000, SIGMA ${ }^{\oplus}$ F1804 and F2425), anti-mono-ADPr AbD33205 (1:1000) ${ }^{34}$, Anti-H3S10-p (1:1000, Bethyl ${ }^{\oplus}$ A301-844A-T, and Abcam ${ }^{\oplus}$ ab5176). Global ADP-ribosylation sigma was detected using the reagent anti-PANADPr (1:2000, Merk ${ }^{\circ}$ MABE1016). Appropriate HRP-conjugated secondary antibodies were used anti-mouse $\left(1 ; 10000\right.$, DAKO$\left.^{\circ}\right)$, anti-rabbit $\left(1 ; 10000\right.$, DAKO$\left.^{\circ}\right)$, anti-goat $\left(1 ; 10000, \mathrm{DAKO}^{\circ}\right)$ and anti-human $(1: 5000)^{34}$. Immuno-reactive bands were detected by chemo-luminescence induced by Immobilon western substrate $\left(\right.$ Millipore $\left.^{\oplus}\right)$, detected with the LI-COR ${ }^{\oplus}$ Odyssey-Fc machine and quantified using Image-Studio ${ }^{\circ}$ software.

Immunofluorescence microscopy. Cells were plated onto glass coverslips and allowed to attach. Cells were fixed with $4 \%$ paraformaldehyde (AlfaAesar ${ }^{\circ}$ ) for $15 \mathrm{~min}$. Where necessary, prior to fixation, soluble protein was pre-extracted using $0.5 \%$ Triton X-100 in KK2 for $5 \mathrm{~min}$ at $4{ }^{\circ} \mathrm{C}$. Cells were then permeabilised in $0.5 \%$ Triton X-100 in KK2 for $10 \mathrm{~min}$, and blocked in $1 \%$ bovine serum albumin $\left(\right.$ Sigma $\left.{ }^{\circ}\right)$ for $1 \mathrm{~h}$. Coverslips were stained with primary antibody $(2 \mathrm{~h}$, room temperature) against H3S10-P (1:500, Bethyl $\left.{ }^{\top} \mathrm{A} 301-844 \mathrm{~A}-\mathrm{T}\right)$ or $\gamma \mathrm{H} 2 \mathrm{AX}(1 / 500$, Abcam $^{\oplus}$ ab11174), washed extensively in KK2-0.01\% Tween- $20^{\circ}$, and stained with fluorescently labelled secondary antibody $(2 \mathrm{~h}$, room temperature) anti-mouse FITC (1:500, DAKO ${ }^{\oplus}$, F0232) or anti-rabbit TRITC (1:500, DAKO ${ }^{\oplus}$, R0156). Following further washing, cells were mounted onto slides in Vectashield ${ }^{\star}$ containing DAPI (Vector Laboratories). Samples were visualised using a microscope Zeiss IX71 equipped with a 10X dry objective and a 100X oil immersion objective lens and a Hamamatsu ${ }^{\oplus}$ Orca- $\mathrm{R}^{2}$ camera. Pictures were analysed with Image ${ }^{\circ}$ software.

Live cell imaging. To monitor mitosis, we expressed GFP-H2B in the cells. Asynchronous cells were treated with $100 \mu \mathrm{g} / \mathrm{ml}$ of phleomycin for $1 \mathrm{~h}$, then washed twice with LoFlo (Formedium ${ }^{\circ}$ LF1001). The cells were transferred on LoFlo agar, then squares of the agar were excised and inverted onto glass bottom imaging dishes and covered with mineral oil. Cells were imaged on a Nikon A1R confocal microscope with a $\times 601.4 \mathrm{NA}$ oil objective. 3D stacks were captured at multiple positions every $30 \mathrm{~s}$ between 2 and $6 \mathrm{~h}$ after phleomycin treatment. Images were analysed as 2D projections of the original 3D stacks with Volocity software, version 6.3 (PerkinElmer). Graphs of data were constructed using Excel 2016.

Reporting summary. Further information on research design is available in the Nature Research Reporting Summary linked to this article.

\section{Data availability}

The datasets generated during and/or analysed during the current study are available from the corresponding author on reasonable request. Source data are provided as a Source Data file. Source data are provided with this paper.

Received: 5 March 2021; Accepted: 19 December 2021; Published online: 13 January 2022

\section{References}

1. Gibson, B. A. \& Kraus, W. L. New insights into the molecular and cellular functions of poly(ADP-ribose) and PARPs. Nat. Rev. Mol. Cell Biol. 13 411-424 (2012).

2. Martin-Hernandez, K., Rodriguez-Vargas, J. M., Schreiber, V. \& Dantzer, F. Expanding functions of ADP-ribosylation in the maintenance of genome integrity. Semin. Cell Dev. Biol. 63, 92-101 (2017).

3. Azarm, K. \& Smith, S. Nuclear PARPs and genome integrity. Genes Dev. 34, 285-301 (2020).

4. Caldecott, K. W. Single-strand break repair and genetic disease. Nat. Rev. Genet. 9, 619-631 (2008).

5. Ronson, G. E. et al. PARP1 and PARP2 stabilise replication forks at base excision repair intermediates through Fbh1-dependent Rad51 regulation. Nat. Commun. 9, 746 (2018).

6. Hanzlikova, H., Gittens, W., Krejcikova, K., Zeng, Z. \& Caldecott, K. W. Overlapping roles for PARP1 and PARP2 in the recruitment of endogenous XRCC1 and PNKP into oxidized chromatin. Nucleic Acids Res. 45, 2546-2557 (2017).

7. Hewitt, G. et al. Defective ALC1 nucleosome remodeling confers PARPi sensitization and synthetic lethality with HRD. Mol. Cell 81, 767-783 (2020).

8. Blessing, C. et al. The oncogenic helicase ALC1 regulates PARP inhibitor potency by trapping PARP2 at DNA breaks. Mol. Cell 80, 862-875 e866 (2020).

9. Juhasz, S. et al. The chromatin remodeler ALC1 underlies resistance to PARP inhibitor treatment. Sci. Adv. 6, eabb8626 (2020).
10. Verma, P. et al. ALC1 links chromatin accessibility to PARP inhibitor response in homologous recombination-deficient cells. Nat. Cell Biol. 23 , 160-171 (2021)

11. Rulten, S. L. et al. PARP-3 and APLF function together to accelerate nonhomologous end-joining. Mol. Cell 41, 33-45 (2011).

12. Beck, C. et al. PARP3 affects the relative contribution of homologous recombination and nonhomologous end-joining pathways. Nucleic Acids Res. 42, 5616-5632 (2014).

13. Luijsterburg, M. S. et al. PARP1 links CHD2-mediated chromatin expansion and H3.3 deposition to DNA Repair by non-homologous end-joining. Mol. Cell 61, 547-562 (2016).

14. McVey, M. \& Lee, S. E. MMEJ repair of double-strand breaks (director's cut): deleted sequences and alternative endings. Trends Genet.: TIG 24, 529-538 (2008).

15. Hanzlikova, H. et al. The importance of Poly(ADP-Ribose) polymerase as a sensor of unligated Okazaki fragments during DNA replication. Mol. Cell 71, 319-331 e313 (2018).

16. Bryant, H. E. et al. PARP is activated at stalled forks to mediate Mre11dependent replication restart and recombination. EMBO J. 28, 2601-2615 (2009).

17. Sugimura, K., Takebayashi, S., Taguchi, H., Takeda, S. \& Okumura, K. PARP1 ensures regulation of replication fork progression by homologous recombination on damaged DNA. J. Cell Biol. 183, 1203-1212 (2008).

18. Yang, Y. G., Cortes, U., Patnaik, S., Jasin, M. \& Wang, Z. Q. Ablation of PARP-1 does not interfere with the repair of DNA double-strand breaks, but compromises the reactivation of stalled replication forks. Oncogene $\mathbf{2 3}$, 3872-3882 (2004).

19. Berti, M. et al. Human RECQ1 promotes restart of replication forks reversed by DNA topoisomerase I inhibition. Nat. Struct. Mol. Biol. 20, 347-354 (2013).

20. Hottiger, M. O. Nuclear ADP-ribosylation and its role in chromatin plasticity, cell differentiation, and epigenetics. Annu. Rev. Biochem. 84, 227-263 (2015).

21. Jungmichel, S. et al. Proteome-wide identification of poly(ADP-Ribosyl)ation targets in different genotoxic stress responses. Mol. Cell 52, 272-285 (2013).

22. Zhang, Y., Wang, J., Ding, M. \& Yu, Y. Site-specific characterization of the Asp- and Glu-ADP-ribosylated proteome. Nat. Methods 10, 981-984 (2013).

23. Leidecker, O. et al. Serine is a new target residue for endogenous ADPribosylation on histones. Nat. Chem. Biol. 12, 998-99 (2016).

24. Bonfiglio, J. J. et al. Serine ADP-ribosylation depends on HPF1. Mol. cell 65 , 932-940 e936 (2017)

25. Larsen, S. C., Hendriks, I. A., Lyon, D., Jensen, L. J. \& Nielsen, M. L. Systems-wide analysis of serine ADP-ribosylation reveals widespread occurrence and site-specific overlap with phosphorylation. Cell Rep. 24, 2493-2505 e2494 (2018).

26. Huang, D. et al. Functional interplay between histone H2B ADP-ribosylation and phosphorylation controls adipogenesis. Mol. cell 79, 934-949 e914 (2020).

27. Chen, Q. et al. ADP-ribosylation of histone variant $\mathrm{H} 2 \mathrm{AX}$ promotes base excision repair. EMBO J. 40, e104542 (2020).

28. Karch, K. R., Langelier, M. F., Pascal, J. M. \& Garcia, B. A. The nucleosomal surface is the main target of histone ADP-ribosylation in response to DNA damage. Mol. Biosyst. 13, 2660-2671 (2017).

29. Gibson, B. A. et al. Chemical genetic discovery of PARP targets reveals a role for PARP-1 in transcription elongation. Science 353, 45-50 (2016).

30. Gibbs-Seymour, I., Fontana, P., Rack, J. G. \& Ahel, I. HPF1/C4orf27 is a PARP-1-interacting protein that regulates PARP-1 ADP-ribosylation activity. Mol. Cell 62, 432-442 (2016).

31. Palazzo L. et al. Serine is the major residue for ADP-ribosylation upon DNA damage. Elife 7, e34334 (2018).

32. Bartlett, E. et al. Interplay of histone marks with serine ADP-ribosylation. Cell Rep. 24, 3488-3502 e3485 (2018)

33. Liszczak, G., Diehl, K. L., Dann, G. P. \& Muir, T. W. Acetylation blocks DNA damage-induced chromatin ADP-ribosylation. Nat. Chem. Biol. 14, 837-840 (2018).

34. Bonfiglio, J. J. et al. An HPF1/PARP1-based chemical biology strategy for exploring ADP-ribosylation. Cell 183, 1086-108 (2020).

35. Couto, C. A. et al. PARP regulates nonhomologous end joining through retention of Ku at double-strand breaks. J. Cell Biol. 194, 367-375 (2011).

36. Hsu, D. W., Gaudet, P., Hudson, J. J., Pears, C. J. \& Lakin, N. D. DNA damage signaling and repair in Dictyostelium discoideum. Cell Cycle 5, 702-708 (2006).

37. Hsu, D. W. et al. DNA double-strand break repair pathway choice in Dictyostelium. J. Cell Sci. 124, 1655-1663 (2011).

38. Hudson, J. J. et al. DNA-PKcs-dependent signaling of DNA damage in Dictyostelium discoideum. Curr. Biol. 15, 1880-1885 (2005).

39. Pears, C. J. \& Lakin, N. D. Emerging models for DNA repair: Dictyostelium discoideum as a model for nonhomologous end-joining. DNA Repair (Amst.) 17, 121-131 (2014).

40. Couto, C. A. et al. Nonhomologous end-joining promotes resistance to DNA damage in the absence of an ADP-ribosyltransferase that signals DNA single strand breaks. J. Cell Sci. 126, 3452-3461 (2013). 
41. Gunn, A. R. et al. The role of ADP-ribosylation in regulating DNA interstrand crosslink repair. J. Cell Sci. 129, 3845-3858 (2016).

42. Kolb, A. L., Gunn, A. R. \& Lakin, N. D. Redundancy between nucleases required for homologous recombination promotes PARP inhibitor resistance in the eukaryotic model organism Dictyostelium. Nucleic Acids Res. 45, 10056-10067 (2017).

43. Kolb, A. L. et al. Dictyostelium as a model to assess site-specific ADPribosylation events. Methods Mol. Biol. 1813, 125-148 (2018).

44. Dubin, M., Fuchs, J., Graf, R., Schubert, I. \& Nellen, W. Dynamics of a novel centromeric histone variant $\mathrm{CenH} 3$ reveals the evolutionary ancestral timing of centromere biogenesis. Nucleic Acids Res. 38, 7526-7537 (2010).

45. Hsu, D. W., Chubb, J. R., Muramoto, T., Pears, C. J. \& Mahadevan, L. C. Dynamic acetylation of lysine-4-trimethylated histone $\mathrm{H} 3$ and $\mathrm{H} 3$ variant biology in a simple multicellular eukaryote. Nucleic Acids Res. 40, 7247-7256 (2012).

46. Stevense, M., Chubb, J. R. \& Muramoto, T. Nuclear organization and transcriptional dynamics in Dictyostelium. Dev. Growth Differ. 53, 576-586 (2011).

47. Chubb, J. R. et al. Developmental timing in Dictyostelium is regulated by the Set1 histone methyltransferase. Dev. Biol. 292, 519-532 (2006).

48. Sawarkar, R., Visweswariah, S. S., Nellen, W. \& Nanjundiah, V. Histone deacetylases regulate multicellular development in the social amoeba Dictyostelium discoideum. J. Mol. Biol. 391, 833-848 (2009).

49. Lohia, R. et al. Deletion of Dictyostelium discoideum Sir2A impairs cell proliferation and inhibits autophagy. J. Biosci. 43, 351-364 (2018).

50. Rakhimova, A. et al. Site-specific ADP-ribosylation of histone H2B in response to DNA double strand breaks. Sci. Rep. 7, 43750 (2017).

51. Asano, Y. et al. Knock-in and precise nucleotide substitution using nearPAMless engineered Cas9 variants in Dictyostelium discoideum. Sci Rep 11, 11163 (2021).

52. Hendriks, I. A., Larsen, S. C. \& Nielsen, M. L. An advanced strategy for comprehensive profiling of ADP-ribosylation sites using mass spectrometrybased proteomics. Mol. Cell Proteom. 18, 1010-1026 (2019).

53. Wang, F. \& Higgins, J. M. Histone modifications and mitosis: countermarks, landmarks, and bookmarks. Trends Cell Biol. 23, 175-184 (2013).

54. Fontana, P. et al. Serine ADP-ribosylation reversal by the hydrolase ARH3. Elife 6, e28533 (2017).

55. Suskiewicz, M. J. et al. HPF1 completes the PARP active site for DNA damageinduced ADP-ribosylation. Nature 579, 598-59 (2020).

56. Sun, F. H. et al. HPF1 remodels the active site of PARP1 to enable the serine ADP-ribosylation of histones. Nat. Commun. 12, 1028 (2021).

57. Ahel, I. et al. Poly(ADP-ribose)-binding zinc finger motifs in DNA repair/ checkpoint proteins. Nature 451, 81-85 (2008).

58. Vas, A. C., Andrews, C. A., Kirkland Matesky, K. \& Clarke, D. J. In vivo analysis of chromosome condensation in Saccharomyces cerevisiae. Mol. Biol. Cell 18, 557-568 (2007).

59. Mora-Bermudez, F., Gerlich, D. \& Ellenberg, J. Maximal chromosome compaction occurs by axial shortening in anaphase and depends on Aurora kinase. Nat. Cell Biol. 9, 822-U170 (2007).

60. Lavoie, B. D., Hogan, E. \& Koshland, D. In vivo requirements for rDNA chromosome condensation reveal two cell-cycle-regulated pathways for mitotic chromosome folding. Genes Dev. 18, 76-87 (2004).

61. Hirota, T., Lipp, J. J., Toh, B. H. \& Peters, J. M. Histone H3 serine 10 phosphorylation by Aurora B causes HP1 dissociation from heterochromatin. Nature 438, 1176-1180 (2005).

62. Fischle, W. et al. Regulation of HP1-chromatin binding by histone H3 methylation and phosphorylation. Nature 438, 1116-1122 (2005).

63. Wang, F. et al. Histone $\mathrm{H} 3 \mathrm{Thr}-3$ phosphorylation by Haspin positions Aurora $\mathrm{B}$ at centromeres in mitosis. Science 330, 231-235 (2010)

64. Kelly, A. E. et al. Survivin reads phosphorylated histone H3 threonine 3 to activate the mitotic kinase Aurora B. Science 330, 235-239 (2010).

65. Monaco, L. et al. Inhibition of Aurora-B kinase activity by poly(ADP-ribosyl) ation in response to DNA damage. Proc. Natl Acad. Sci. USA 102, 14244-14248 (2005).

66. Slade, D. Mitotic functions of poly(ADP-ribose) polymerases. Biochem. Pharmacol. 167, 33-43 (2019).
67. Halappanavar, S. S. \& Shah, G. M. Defective control of mitotic and postmitotic checkpoints in poly(ADP-ribose) polymerase-1(-/-) fibroblasts after mitotic spindle disruption. Cell Cycle 3, 335-342 (2004).

68. Kanai, M. et al. Involvement of poly(ADP-ribose) polymerase 1 and poly(ADP-ribosyl)ation in regulation of centrosome function. Mol. Cell. Biol. 23, 2451-2462 (2003).

69. Menissier de Murcia, J. et al. Functional interaction between PARP-1 and PARP-2 in chromosome stability and embryonic development in mouse. EMBO J. 22, 2255-2263 (2003).

70. Tong, W. M. et al. Poly(ADP-ribose) polymerase-1 plays a role in suppressing mammary tumourigenesis in mice. Oncogene 26, 3857-3867 (2007)

71. Gemble, S. et al. Pyrimidine pool disequilibrium induced by a cytidine deaminase deficiency inhibits PARP-1 activity, leading to the under replication of DNA. PLoS Genet. 11, e1005384 (2015).

\section{Acknowledgements}

NDL's laboratory and J.B. are supported by the Medical Research Council (www.mrc.ac.uk; MR/P028284/1; MR/V00896X/1). J.B. was supported by the EP Abraham Cephalosporin Fund. TM was supported by JSPS KAKENHI (grant number: 20K06659). We thank Ivan Matic (Max Planck Institute for Biology of Ageing, Cologne, Germany) for the Anti Ser-ADPr antibody (AbD33205), NBRP Nenkin for providing some of the plasmids, and members of NDL and CP labs for discussions.

\section{Author contributions}

All experiments were performed by J.B. with the exceptions of J.E. assisting with the H3b immunoprecipitation analysis and TM/KF performing the live cell imaging analysis. N.D.L., J.B. and C.P. wrote the manuscript.

\section{Competing interests}

The authors declare no competing interests.

\section{Additional information}

Supplementary information The online version contains supplementary material available at https://doi.org/10.1038/s41467-021-27867-4.

Correspondence and requests for materials should be addressed to Nicholas D. Lakin.

Peer review information Nature Communications thanks the anonymous reviewer(s) for their contribution to the peer review of this work.

Reprints and permission information is available at http://www.nature.com/reprints

Publisher's note Springer Nature remains neutral with regard to jurisdictional claims in published maps and institutional affiliations.

\footnotetext{
(c) (1) Open Access This article is licensed under a Creative Commons Attribution 4.0 International License, which permits use, sharing, adaptation, distribution and reproduction in any medium or format, as long as you give appropriate credit to the original author(s) and the source, provide a link to the Creative Commons license, and indicate if changes were made. The images or other third party material in this article are included in the article's Creative Commons license, unless indicated otherwise in a credit line to the material. If material is not included in the article's Creative Commons license and your intended use is not permitted by statutory regulation or exceeds the permitted use, you will need to obtain permission directly from the copyright holder. To view a copy of this license, visit http://creativecommons.org/ licenses/by/4.0/.
}

(C) The Author(s) 2022 